\title{
ARTICLE
}

Cite this: DOI: $10.1039 / \times 0 \times x 00000 x$

\section{TMP (2,2,6,6-Tetramethylpiperidide)-Aluminate Bases: Lithium-Mediated Alumination or Lithiation/Alkylaluminium-Trapping Reagents?}

Received 00th January 2012 Accepted 00th January 2012

DOI: $10.1039 / \times 0 \times x 00000 x$

www.rsc.org/

\author{
David R. Armstrong, ${ }^{a}$ Elaine Crosbie, ${ }^{a}$ Eva Hevia, ${ }^{a}$ Robert E. Mulvey, ${ }^{a *}$ \\ Donna L. Ramsay ${ }^{a *}$ and Stuart D. Robertson ${ }^{a}$
}

\section{Introduction}

The changing landscape of metallation over the past decade or so has seen the growth of a forest of new metallating agents. Now metals such as magnesium, zinc, and aluminium, in particular, and copper and manganese to a lesser extent, stand tall beside lithium as capable of executing metal-hydrogen exchange on a myriad of aromatic and heteroaromatic substrates. Moreover these fundamentally important reactions of this new set of metal reagents can often offer general advantages (most significantly, improved functional group tolerance, milder reaction conditions, greater compatibility with tandem transition metal catalysed bond forming strategies) over those executed by long established lithium alkyl ${ }^{1}$ and lithium amide $^{2}$ reagents. Less electropositive than lithium, these other metals form less polar and consequently less reactive organometallic compounds than organolithium reagents so activation is required to adapt them for metallation applications. Two types of activation are common. Stoichiometric lithium chloride can be added to fashion mixed organometallic-salt systems typified by the turbo-Hauser reagent $(\mathrm{TMP}) \mathrm{MgCl} \cdot \mathrm{LiCl}$ (TMP is 2,2,6,6-tetramethylpiperidide). ${ }^{3}$ Though salt additive effects have long been recognised, Knochel has masterminded a remarkable row of reagents of this type based upon them. ${ }^{4}$ Activation can also be realised through mixed organometallicorganometallic systems where one metal is an alkali metal and the second is one of the aforementioned nominally less reactive metals. $^{5} \quad$ Amido-alkyl combinations typified by $\mathrm{LiTMP} \cdot \mathrm{Zn}\left({ }^{\mathrm{t}} \mathrm{Bu}\right)_{2}{ }^{6}$ and (TMEDA) $\mathrm{Na}\left({ }^{\mathrm{n}} \mathrm{Bu}\right) \cdot \mathrm{Mg}(\mathrm{TMP})_{2}{ }^{7}$ which can also be regarded as ates (zincate and magnesiate respectively) have proved the best metallating agents in this category - note all-alkyl combinations show a greater tendency for nucleophilic addition. ${ }^{8}$ While in metallation reactions the efficiency and scope of these new activated systems have generally been well studied, by comparison definite information on them in their own right has been rather thin on the ground prompting some to be likened to black box reagents. ${ }^{9}$ 

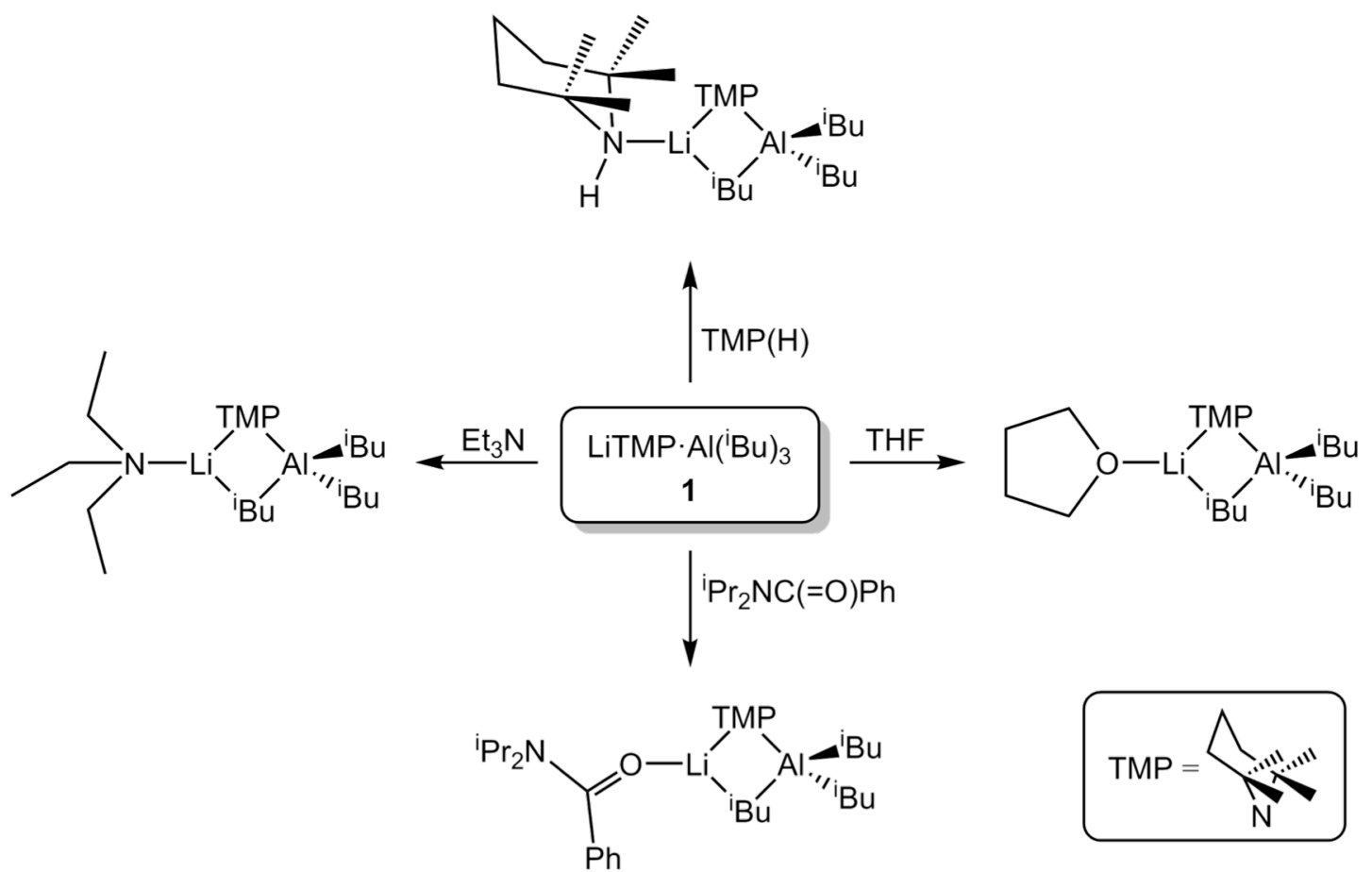

Scheme 1. Lewis base mediated co-complexation reactions of LiTMP and $\mathrm{Al}\left(\mathrm{B}^{\mathrm{i}} \mathrm{Bu}\right)_{3}$ in bulk hexane solution.

A particularly attractive branch of this multicomponent ate chemistry is alkali-metal-mediated alumination (AMMAI) due to the high abundance, comparative cheapness, low toxicity and recycling opportunities of the group 13 metal as well as the documented halogen tolerance of lithium aluminates. ${ }^{10}$ It was in the course of comparing the two reagents that dominate AMMAI chemistry, Uchiyama and Wheatley's "LiTMP-Al( $\left.{ }^{\mathrm{i}} \mathrm{Bu}\right)_{3} " \mathbf{1}^{11}$ and our own bis-TMP version "LiTMP-Al(TMP) $\left({ }^{\mathrm{i}} \mathrm{Bu}\right)_{2}$ " $2{ }^{12}$ in reactions with polydentate Lewis bases, ${ }^{13}$ and stimulated further by Knochel's intriguing report of the turbo-Hauser base analogue "TMPMgCl$\cdot \mathrm{LiCl} \cdot \mathrm{AlEt}_{3}$ ", ${ }^{14}$ that we had cause to revisit these key reagents in their own right. Though both have been studied previously the direct comprehensive comparison between them made here through new NMR (including DOSY) spectroscopic studies, reactivity observations and DFT calculations uncovers several remarkable and surprising findings that provide a more complete picture of these complicated multicomponent base mixtures. Specifically doubt is cast on in situ $\mathbf{1}$ being a single species in THF solution and on the existence of $\mathbf{2}$ as a mixedmetal species either in hexane or THF solution. The most extraordinary revelation from this work is that neither $\mathbf{1}$ nor $\mathbf{2}$ appears capable of "aluminating" substrates in THF solution through a lithium aluminate species, so calling into question the term alkali-metal-mediated alumination (AMMAI) to describe their metallation applications in this medium. Instead evidence points to these being lithiation reactions, the generated carbanions of which are rapidly trapped by alkylaluminium species to form aluminate products. ${ }^{15}$

\section{Results and Discussion}

Has the active base of 1 been crystallographically characterised?

In the original preparation of $\mathbf{1}$ reported by Uchiyama in $2004,{ }^{11 a}$ LiTMP prepared in situ by the action of $n$-butyllithium on $\operatorname{TMP}(\mathrm{H})$ at $-78^{\circ} \mathrm{C}$ was subsequently treated with triisobutylaluminium and the mixture was warmed to $0^{\circ} \mathrm{C}$. The bulk solvent employed was THF (in an approximate 25 molar excess on a $2 \mathrm{mmol}$ scale reaction) though the mixture also contained hexane from the lithium and aluminium reagent solutions employed. Evidence that LiTMP and triisobutylaluminium can interact with each other under the mediation of a Lewis base $\mathrm{L}$ to forge co-complexes of the type $\left[\mathrm{L} \cdot \mathrm{Li}(\mu-\mathrm{TMP})\left(\mu-{ }^{\mathrm{i}} \mathrm{Bu}\right) \mathrm{Al}\left({ }^{\mathrm{i}} \mathrm{Bu}\right)_{2}\right]$ came from our crystallographic characterisation of three examples where $\mathrm{L}$ is $\mathrm{N}, \mathrm{N}$ diisopropylbenzamide, TMP $(\mathrm{H})$ or triethylamine (Scheme 1$).{ }^{16}$ Going one step better, Naka, Uchiyama and Wheatley subsequently crystallographically characterised an aluminate compound containing all the components of the base reaction mixture 1 in the mono-THF complex $[(\mathrm{THF}) \cdot \operatorname{Li}(\mu-\mathrm{TMP})(\mu-$ $\left.\left.{ }^{\mathrm{i}} \mathrm{Bu}\right) \mathrm{Al}\left({ }^{\mathrm{i}} \mathrm{Bu}\right)_{2}\right] \quad \mathbf{1} \cdot \mathbf{T H F} \quad($ Scheme 1$) .{ }^{11 \mathrm{~b}}$ These Lewis base stabilised aluminates have in common contacted ion pair structures where $\mathrm{Li}$ and $\mathrm{Al}$ connect through ligand bridges. Significantly the crystals of all of these compounds were grown in bulk hydrocarbon solutions. The most experimentally relevant set of $\mathbf{1}$. THF were crystallised from a bulk hexane solution containing a stoichiometric deficiency of THF $[0.625$ mmol per $1 \mathrm{mmol}$ of "LiTMP·Al $\left.\left({ }^{\mathrm{i}} \mathrm{Bu}\right)_{3}{ }_{3}\right] \cdot{ }^{17}$ However the base mixture $\mathbf{1}$ is prepared and utilised in a vast excess of THF in its 


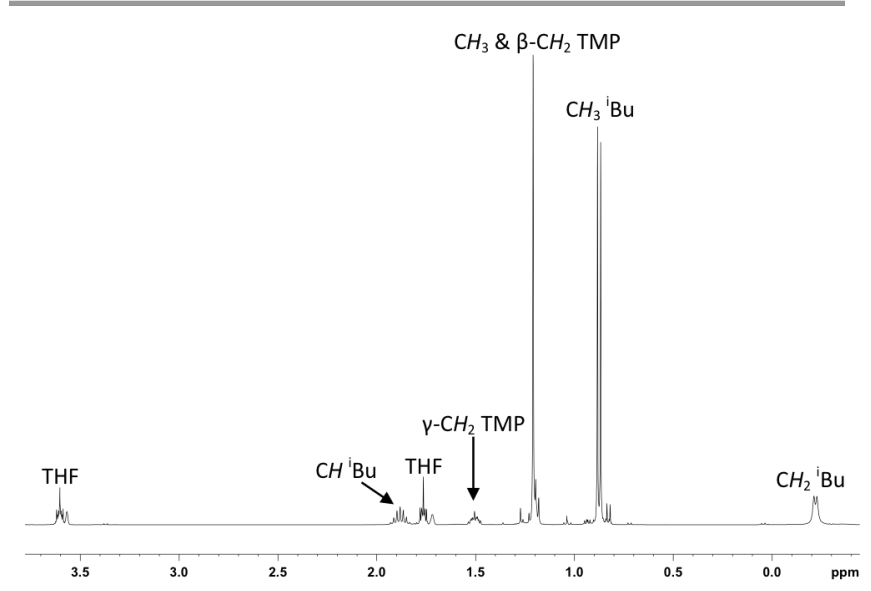

Figure 1. ${ }^{1} \mathrm{H}$ NMR spectrum of crystalline THF-LiTMP.Al('Bu $)_{3} 1 \cdot$ THF in $d_{8}$-THF solution in which it forms solvent-separated $\left[\left\{\mathrm{Li}(\mathrm{THF})_{4}\right\}^{+}\left\{\mathrm{Al}(\mathrm{TMP})(\mathrm{Bu})_{3}\right\}^{-}\right]$ $\mathbf{1 \cdot ( T H F )})_{4}$.

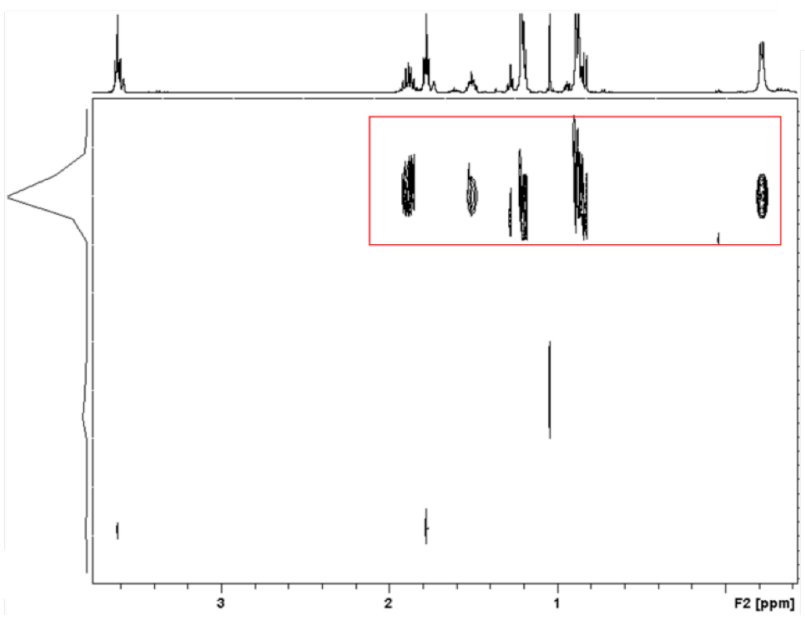

Figure 2. DOSY ${ }^{1} \mathrm{H}$ NMR spectrum of crystalline THF.LiTMP.Al('Bu) ${ }_{3}$ 1.THF in $d_{8}$-THF solution. Note that a trace amount of TMP(H) is evident at $1.04 \mathrm{ppm}$.

synthetic applications so the question requiring an answer is "does 1·THF represent the experimental base in the THF solution mixture of $\mathbf{1}$ ?"

Towards answering this question in this new study we prepared 1.THF in crystalline form following the aforementioned literature procedure and dissolved it in neat $\mathrm{d}_{8}$-THF to replicate the environment it is employed in during successful AMMAI applications. Recording the ${ }^{1} \mathrm{H}$ NMR spectrum at ambient temperature revealed a simple pattern showing one set of ${ }^{\mathrm{i}} \mathrm{Bu}$ and TMP resonances consistent with a single solution species (Figure 1). Supporting this single species assignment, the ${ }^{7} \mathrm{Li}$ NMR spectrum shows a sharp single resonance at $1.21 \mathrm{ppm}$. Re-running the ${ }^{1} \mathrm{H}$ NMR spectra at elevated temperatures (from 300 to $330 \mathrm{~K}$ ) did not change this pattern. A DOSY ${ }^{1} \mathrm{H}$ NMR ${ }^{18}$ spectrum (Figure 2) of this $\mathrm{d}_{8}$-THF solution of crystalline 1. THF showed that all of the resonances of the aluminate moiety (that is ${ }^{\mathrm{i}} \mathrm{Bu}, \mathrm{CH}_{2},-0.22 \mathrm{ppm} ; \mathrm{CH}_{3}, 0.88 \mathrm{ppm}$; $\mathrm{CH}, 1.88$ ppm: TMP, $\mathrm{CH}_{3}, 1.21$ ppm; $\beta-\mathrm{CH}_{2}, 1.20 \mathrm{ppm} ; \gamma-\mathrm{CH}_{2}, 1.51$ ppm) lie along the same line on the y-axis with essentially the same diffusion coefficient $\left(6.95 \times 10^{-10} \pm 0.09 \times 10^{-10} \mathrm{~m}^{2} / \mathrm{s}\right)$ implying that the two distinct ligands belong to the same compound/structure. Only the THF resonances (at 1.78 and $3.61 \mathrm{ppm}$ ) of the $\mathbf{1} \cdot \mathbf{T H F}$ formulation lie outside of this line. The obvious explanation is that THF is labile and hence could be undergoing a metal-attached coordinative, metal-free decoordinative equilibrium in $\mathrm{d}_{8}$-THF solution. These resonances appear lower down the $\mathrm{y}$-axis as the THF has a smaller molecular weight and thus a higher diffusion coefficient $\left(2.05 \times 10^{-9} \pm 0.01 \times 10^{-10} \mathrm{~m}^{2} / \mathrm{s}\right)$ than the "LiTMP.Al $\left({ }^{\mathrm{i}} \mathrm{Bu}\right)_{3}$ " portion of crystalline $1 \cdot \mathbf{T H F}$. The obvious assignment for this single species in a vast pool of excess THF is the solventseparated ion pair $\left[\left\{\mathrm{Li}(\mathrm{THF})_{4}\right\}^{+}\left\{\mathrm{Al}(\mathrm{TMP})\left({ }^{\mathrm{i}} \mathrm{Bu}\right)_{3}\right\}^{-}\right] \mathbf{1} \cdot(\mathbf{T H F})_{4}$. Supporting this assignment a comparatively broad resonance at $139.8 \mathrm{ppm}$ is found in the ${ }^{27} \mathrm{Al} \mathrm{NMR}$ spectrum in $\mathrm{d}_{8}$-THF solution consistent with an asymmetrical $\left[\left\{\mathrm{Al}(\mathrm{TMP})\left({ }^{\mathrm{i}} \mathrm{Bu}\right)_{3}\right\}^{-}\right]$ ion and as aforementioned its ${ }^{7} \mathrm{Li}$ NMR spectrum shows a singlet resonance at $1.21 \mathrm{ppm}$ which coincides exactly with the ${ }^{7} \mathrm{Li} \quad \mathrm{NMR}$ spectrum of the ate compound $\left[\left\{\mathrm{Li}(\mathrm{THF})_{4}\right\}^{+}\left\{\mathrm{Al}\left({ }^{\mathrm{i}} \mathrm{Bu}\right)_{4}\right\}^{-}\right]$implying that the separated $\left\{\mathrm{Li}(\mathrm{THF})_{4}\right\}^{+}$cation is common to both ates [note though that the chemical shift for the $\left\{\mathrm{Li}(\mathrm{THF}\}_{4}\right]^{+}$cation is highly sensitive to changes in concentration - see Figure S1(b) in ESI for an example]. It is well known that low local symmetry around Al centres in general, ${ }^{19}$ and indeed specifically in TMP attached systems leads to broad signals [in (TMP) ${ }_{2} \mathrm{AlX}$ systems they can be hundreds or even thousands of $\mathrm{Hz}$ broad]. ${ }^{20}$

\section{$2\left[\mathrm{Li}(\mathrm{TMP}) \cdot \mathrm{Al}\left({ }^{\mathrm{i}} \mathrm{Bu}\right)_{3}\right]$}<smiles>F[In](F)F</smiles>

\section{$2 "\left[\left\{\mathrm{Li}(\mathrm{THF})_{4}\right\}^{+}\left\{\mathrm{Al}(\mathrm{TMP})\left({ }^{\mathrm{B}} \mathrm{Bu}\right)_{3}\right\}^{-}\right]^{\prime}$ $1 \cdot(\mathrm{THF})_{4}$}<smiles>C=C</smiles>

\section{$\left[\left\{\mathrm{Li}(\mathrm{THF})_{4}\right\}^{+}\left\{\mathrm{Al}(\mathrm{TMP})_{2}\left({ }^{\mathrm{B}} \mathrm{Bu}\right)_{2}\right\}^{-}\right]+\left[\left\{\mathrm{Li}(\mathrm{THF})_{4}\right\}^{+}\left\{\mathrm{Al}\left({ }^{\mathrm{i}} \mathrm{Bu}\right)_{4}\right\}^{-}\right]$ $2 \cdot(\mathrm{THF})_{4}$ 3}

Scheme 2. The previously postulated dismutation of putative LiTMP.Al('Bu $)_{3}$ 1 in bulk THF solution.

Intriguingly these NMR spectroscopic results from $d_{8}-T H F$ solutions of crystalline $\mathbf{1} \cdot \mathbf{T H F}$ are in discordance with our earlier studies of "LiTMP. $\mathrm{Al}\left({ }^{\mathrm{i}} \mathrm{Bu}\right)_{3}$ " prepared in situ in bulk THF solution. ${ }^{21} \mathrm{~A}$ combination of ${ }^{1} \mathrm{H},{ }^{7} \mathrm{Li}$ and ${ }^{13} \mathrm{C}$ NMR data pointed strongly to the existence of a dismutation process (Scheme 2) in contrast to the single species implicated in the 
$\mathrm{d}_{8}$-THF solution of crystalline 1-THF. The key piece of evidence towards this dismutation was the characterisation of the tetraalkylaluminate $\left[\left\{\mathrm{Li}(\mathrm{THF})_{4}\right\}^{+}\left\{\mathrm{Al}\left({ }^{\mathrm{i}} \mathrm{Bu}\right)_{4}\right\}^{-}\right], 3$ a solventseparated ion pair structure though this was the only species unequivocally identified from the mixture. Arrived at by simply balancing the stoichiometry of the equilibrium reaction, the putative co-product " $\left[\left\{\mathrm{Li}(\mathrm{THF})_{4}\right\}^{+}\left\{\mathrm{Al}(\mathrm{TMP})_{2}\left({ }^{\mathrm{i}} \mathrm{Bu}\right)_{2}\right\}^{-}\right]$", 2.(THF $)_{4}$ inspired us to the idea of employing the bis-TMP species "LiTMP-Al(TMP) $\left({ }^{\mathrm{i}} \mathrm{Bu}\right)_{2}$ ", 2 in AMMAI reactions (see later). Knochel's subsequent discovery that a closely related equilibrium may be operating in THF solution mixtures of $\mathrm{TMPMgCl} \cdot \mathrm{LiCl}$ and $\mathrm{Al}(\mathrm{Et})_{3}$ leading to the tetraalkylaluminate "MgCl$\cdot \mathrm{Al}(\mathrm{Et})_{4}$ " (characterised in part by a sharp resonance at $159 \mathrm{ppm}$ in ${ }^{27} \mathrm{Al}$ NMR spectra) and the alkylaluminium amide (TMP)Al(Et) $)_{2} \cdot \mathrm{THF}^{14}$ motivated us to revisit in greater detail the comparison between the THF solutions of crystalline $\mathbf{1} \cdot \mathbf{T H F}$ and its in situ form 1. Our findings detailed below were unexpected.

\section{Comparative reactivity studies of in situ 1 and crystalline $1 \cdot$ THF with anisole}

A pivotal molecule in the development of directed ortho metallation (DoM) chemistry ${ }^{22}$ in the classical studies of Wittig ${ }^{23}$ and Gilman, ${ }^{24}$ anisole is a benchmark substrate for measuring the performance of metallating agents. Hence there are numerous reports of the ortho metallation of anisole by different metallating reagents. Lithium mono-TMP aluminate 1 is included in this number as in fact anisole was utilised as the model substrate by Uchiyama when this reagent was first introduced. ${ }^{11 \mathrm{a}}$ This original study found that a THF solution of in situ 1 gave a 99\% yield of $o$-iodoanisole following quenching of the metallated intermediate with iodine (Table 1: this table gives the yields of the reactions of anisole with various $\mathrm{Li}-\mathrm{Al}$ and $\mathrm{Al}$ reagents mentioned in this paper). This "AMMAI" was carried out at room temperature for three hours and most significantly the base:anisole stoichiometry employed to achieve this yield was 2.2:1.0 molar equivalents, that is the base was in a slightly greater than twofold excess. Hence this implies that at least $50 \%$ of the base $\mathbf{1}$ is inactive towards anisole under the conditions studied. For comparison in this work we repeated this original reaction but this time using a 1:1, base:anisole stoichiometry in bulk THF solution. That in situ 1 could deprotonate anisole effectively was confirmed by this repeat reaction though significantly the yield of deprotonated anisole observed in a ${ }^{1} \mathrm{H}$ NMR spectrum of $\mathrm{a} \mathrm{d}_{6}$ benzene solution of the reaction mixture only approached $50 \%$ conversion of anisole starting material. This loss of about $50 \%$ of base activity is explicable if the dismutation equilibrium in Scheme 2 lies to the right hand side and if one of the two components, the tetrabutyl aluminate 3 was inactive towards anisole. Previously we had reported that 3 failed to react with $\mathrm{N}, \mathrm{N}$-diisopropylbenzamide ${ }^{21}$ which carries a much stronger ortho-deprotonating directing group than the methoxy substituent of anisole so it was anticipated that 3 would be inert towards anisole in bulk THF solution and a control reaction between them confirmed this view. Moreover we found that $\mathbf{3}$ even failed to deprotonate the acidic $\mathrm{N}-H$ bond of $\mathrm{TMP}(\mathrm{H})$, the co-product obtained when the TMP anion functions as a base. Further proof that tetrabutylaluminate $\mathbf{3}$ is a major component of in situ 1 came from the observation of a sharp resonance at $152.5 \mathrm{ppm}$ in its ${ }^{27} \mathrm{Al}$ NMR spectrum in $\mathrm{d}_{8}$-THF solution that matches that of an authentic sample of 3 . The sharpness of this resonance is consistent with the high degree of symmetry in the tetrahedral Al centre in 3. This sharp resonance (reported at $153.4 \mathrm{ppm})^{25}$ appears to have been wrongly assigned as belonging to putative contacted ion-pair "LiTMP. $\mathrm{Al}\left({ }^{\mathrm{i}} \mathrm{Bu}\right)_{3}$ " $\mathbf{1}$ in an earlier paper. ${ }^{11 \mathrm{~b}} \mathrm{~A}$ highly asymmetrical $\left[\mathrm{Al}(\mathrm{TMP})\left({ }^{\mathrm{i}} \mathrm{Bu}\right)_{3}\right]^{-}$ centre would give rise to a broader resonance which as mentioned earlier appears in our spectrum at $139.8 \mathrm{ppm}$. Note as mentioned above that a similar ${ }^{27} \mathrm{Al}$ chemical shift is found in the related highly symmetrical tetraethylaluminate " $\left[(\mathrm{MgCl})^{+}\left(\mathrm{AlEt}_{4}\right)^{-}\right]$" (at $159 \mathrm{ppm}$ ) as reported by Knochel. ${ }^{14}$ Interestingly when we repeated the original reaction carried out by Uchiyama using a 2.2:1.0 stoichiometric ratio of in situ $\mathbf{1}$ to anisole in THF solution and recorded the NMR spectrum of the metallated intermediate in $\mathrm{d}_{8}$-THF solvent we see lithiated anisole (confirmed by comparison to a spectrum of an authentic sample) as well as aluminated anisole through diagnostic doublet of doublet resonances for the anisolyl meta C- $H$ adjacent to the ortho site of metallation at 7.65 and $7.48 \mathrm{ppm}$

Table 1. Comparative reactivities of various $\mathrm{Li}-\mathrm{Al}$ or $\mathrm{Al}$ reagents towards anisole.

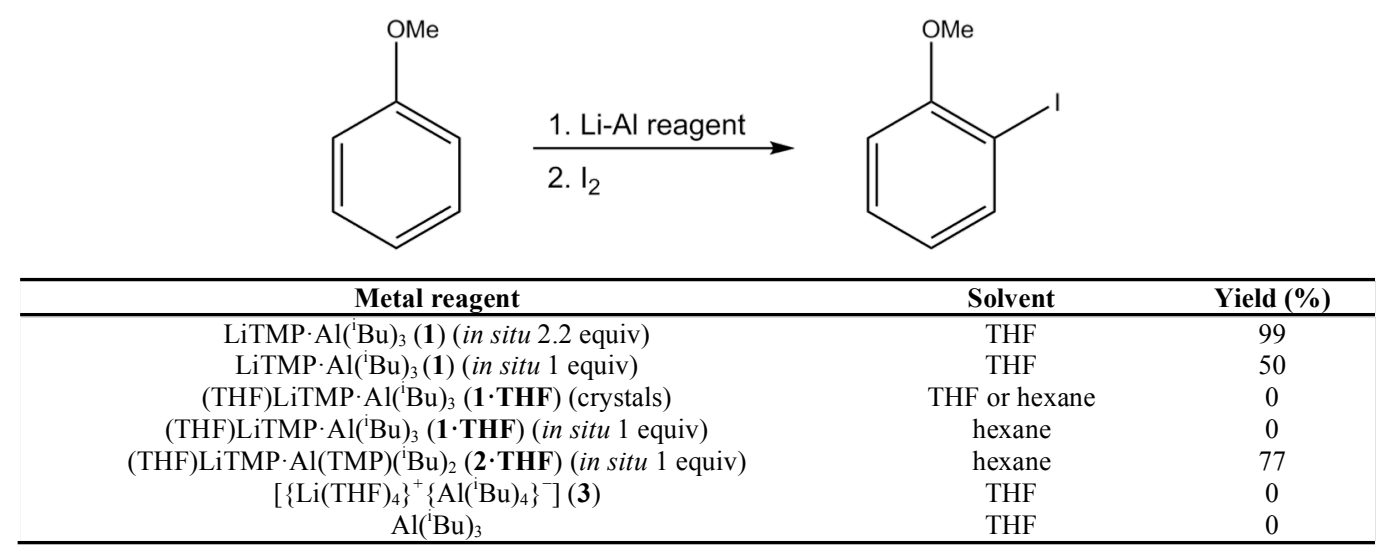


respectively in an appropriate 1:4 ratio (Figure 3). This provided the first strong hint that the reactions of in situ $\mathbf{1}$ are not merely, if at all, aluminium-hydrogen exchange reactions.

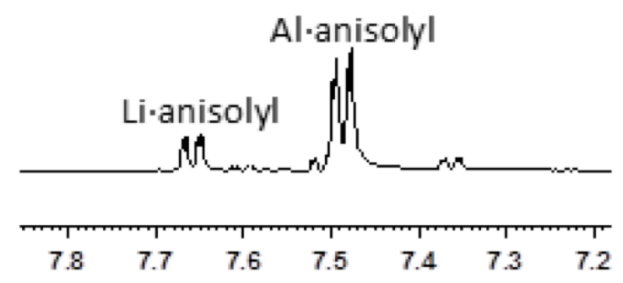

Figure 3. Part of the aryl region of the ${ }^{1} H$ NMR spectrum of the reaction of in situ LiTMP.Al( $(\mathrm{Bu})_{3} 1$ with anisole in $\mathrm{d}_{8}$-THF solution showing both lithiated anisole and aluminated anisole.

Surprisingly, contrasting with the previous straightforward metallation of anisole using in situ prepared 1, on dissolving crystalline 1.THF in THF solution mixed with anisole and stirring the mixture for several hours to replicate the reaction with in situ 1 no reaction was observed to take place (Table 1) as determined from the recovered anisole seen in NMR spectra. The implication of this finding is that once the aluminate structure of $\mathbf{1} \cdot \mathbf{T H F}$, presumably as $\left[\left\{\mathrm{Li}(\mathrm{THF})_{4}\right\}^{+}\left\{\mathrm{Al}(\mathrm{TMP})\left({ }^{\mathrm{i}} \mathrm{Bu}\right)_{3}\right\}^{-}\right], \quad \mathbf{1} \cdot(\mathbf{T H F})_{4}, \quad$ is formed all deprotonative reactivity of the mixture is lost. To probe this idea further $\mathbf{1} \cdot \mathbf{T H F}$ was also prepared in situ in hexane solution by combining its component compounds $\left[\mathrm{Al}\left({ }^{\mathrm{i}} \mathrm{Bu}\right)_{3}\right.$, LiTMP and THF in a 1:1:1 ratio] but even this mixture proved inert towards anisole. Under these poorly solvating conditions the aluminate will almost certainly be in its contacted ion pair form $\left[(\mathrm{THF}) \cdot \mathrm{Li}(\mu-\mathrm{TMP})\left(\mu-{ }^{\mathrm{i}} \mathrm{Bu}\right) \mathrm{Al}\left({ }^{\mathrm{i}} \mathrm{Bu}\right)_{2}\right], \mathbf{1} \cdot \mathbf{T H F}$. On the basis of these pieces of evidence we can conclude with some certainty that $\mathbf{1} \cdot \mathbf{T H F}$ is not the active experimental base in the solution mixture $\mathbf{1}$, that crystalline $\mathbf{1} \cdot \mathbf{T H F}$ does not undergo a dismutation equilibrium in the THF solution akin to that shown for in situ 1 in Scheme 2 but remains as the solvent-separated species 1.(THF) $)_{4}$, and in answer to the question posed the actual active base of $\mathbf{1}$ has therefore seemingly not been crystallographically characterised or more accurately $\left[(\mathrm{THF}) \cdot \mathrm{Li}(\mu-\mathrm{TMP})\left(\mu-{ }^{\mathrm{i}} \mathrm{Bu}\right) \mathrm{Al}\left({ }^{\mathrm{i}} \mathrm{Bu}\right)_{2}\right] \mathbf{1} \cdot \mathbf{T H F}$ is not the active base (but see qualification later).

\section{Towards solving the puzzle of "LiTMP·Al(TMP)('Bu) $)_{2}$ "}

For reasons that will become clear later in the discussion we have been unsuccessful in our several attempts to isolate a solid form let alone a crystalline form of "LiTMP·Al(TMP) $\left({ }^{\mathrm{i}} \mathrm{Bu}\right)_{2}$ ", 2, the putative co-product of the hypothesised dismutation portrayed in Scheme 2. However it was the postulated presence of $\mathbf{2}$ in a THF solvated form $\mathbf{2} \cdot(\mathbf{T H F})_{\mathbf{n}}$ within this equilibrium having the attraction of seemingly possessing extra TMP power (as it is the single TMP ligand in $\mathbf{1}$ that is its active base component) that encouraged us to make a reagent of this twofold TMP stoichiometry. To begin the study of $\mathbf{2}$ here, we recorded the ${ }^{1} \mathrm{H}$ NMR spectra of its individual constituent compounds LiTMP ${ }^{26}$ and (TMP)Al( $\left.{ }^{\mathrm{i}} \mathrm{Bu}\right)_{2},{ }^{12} \boldsymbol{2}$ itself, as well as a 1:1 mixture of 2 and THF in $\mathrm{d}_{14}$-hexane solution (Figure 4). Interestingly this comparison revealed that LiTMP and $(\mathrm{TMP}) \mathrm{Al}\left({ }^{\mathrm{i}} \mathrm{Bu}\right)_{2}$ remain separated as homometallic species.

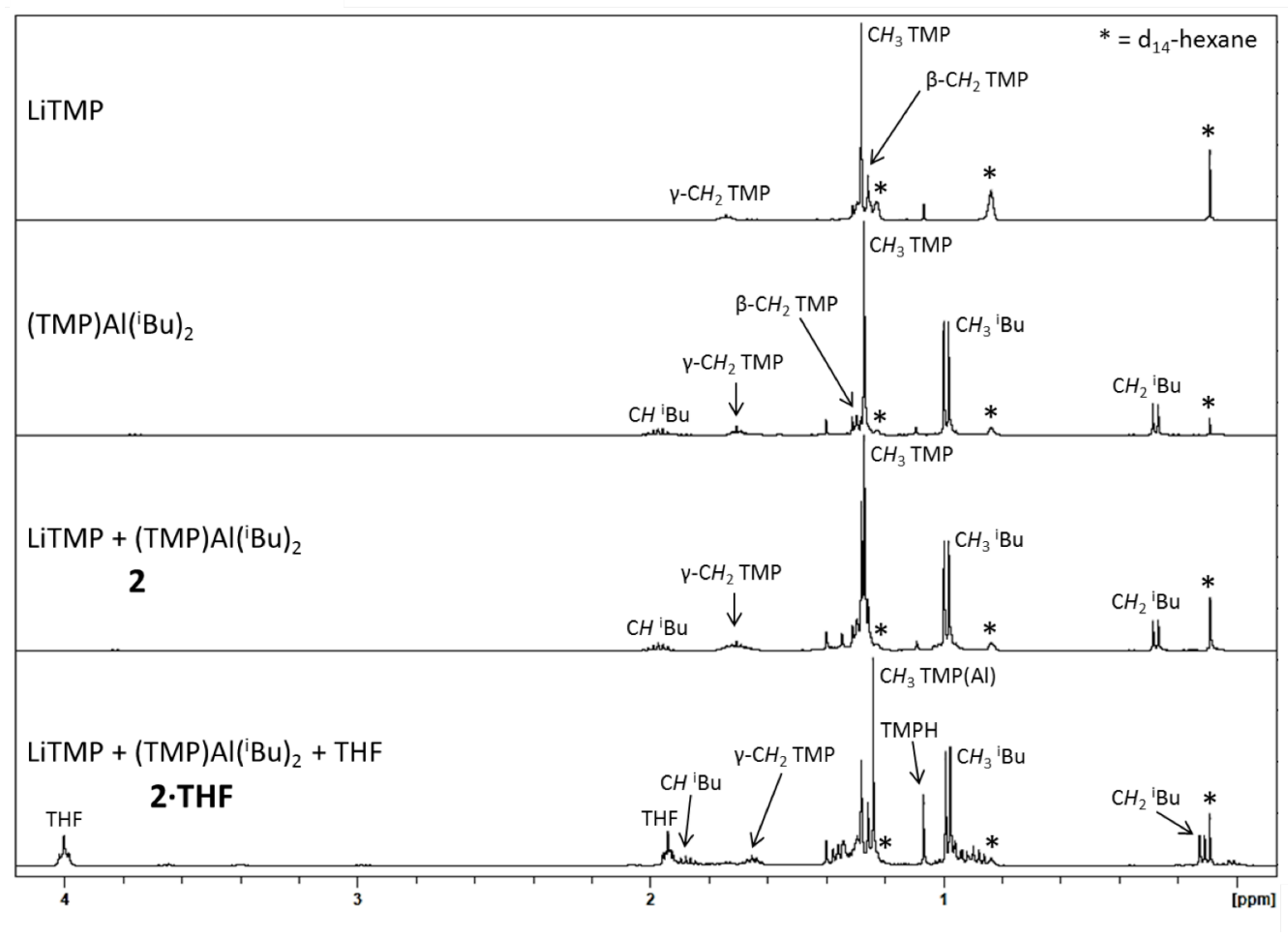

Figure 4. Overlay of ${ }^{1} \mathrm{H}$ NMR spectra of 2 and its component parts in $d_{14}$-hexane solution. 
When stoichiometric THF is introduced it appears to interact preferentially with the Al reagent to afford $\left[(\mathrm{TMP}) \mathrm{Al}\left({ }^{\mathrm{i}} \mathrm{Bu}\right)_{2} \cdot \mathrm{THF}\right]$ which we have previously characterised ${ }^{27}$ as the chemical shifts of the ${ }^{\mathrm{i}} \mathrm{Bu}$ resonances move (most diagnostically the $\mathrm{CH}_{2}$ attached to the metal moves from 0.28 to $0.15 \mathrm{ppm}$ ) together with those for the TMP anion; whereas those of LiTMP remain unchanged. While these species appear to stay separated, it should be noted that there is a precedent for donor-free co-complexation in polymeric $\left[\left\{\mathrm{Li}(\mathrm{TMP}) \mathrm{AlMe}_{3}\right\}_{\infty}\right],{ }^{28}$ though significantly this crystalline compound was formed under much harsher reflux conditions in toluene than the room temperature conditions of our NMR comparison coupled with the fact that its alkyl groups are much smaller than those in 2.

Turning to reactivity issues, earlier studies showed $\mathbf{2} \cdot(\mathbf{T H F})_{\mathbf{n}}$ was an effective base as it executed AMMAl on a range of organic substrates (Scheme 3 ). ${ }^{13}$ Most significantly, 2 (THF) was found to metallate THF in bulk hexane solution as evidenced by the slow appearance of resonances attributed to ortho-deprotonated THF $\left(o-\mathrm{OC}_{4} \mathrm{H}_{7}{ }^{-}\right)$, while addition of a second THF molecule led to the formation of $[(\mathrm{THF}) \cdot \mathrm{Li}(\mu-$ $\left.\mathrm{TMP})\left(\mu-\mathrm{OC}_{4} \mathrm{H}_{7}\right) \mathrm{Al}\left({ }^{\mathrm{i}} \mathrm{Bu}\right)_{2}\right], 4$, which was crystallographically authenticated (See ESI, Figure S9). ${ }^{29}$ Anisole was similarly ortho-aluminated by $\mathbf{2} \cdot(\mathbf{T H F})_{1}$ to generate crystalline $\left[(\mathrm{THF}) \cdot \mathrm{Li}(\mu-\mathrm{TMP})\left(o-\mathrm{C}_{6} \mathrm{H}_{4} \mathrm{OMe}\right) \mathrm{Al}\left({ }^{\mathrm{i}} \mathrm{Bu}\right)_{2}\right], 5$, which in turn could be intercepted by the electrophile iodine to produce $o$ iodoanisole in a 77\% yield (Table 1). ${ }^{12}$ As mentioned previously this behaviour contrasts with that of in situ $\mathbf{1} \cdot \mathbf{T H F}$, which fails to metallate anisole at all in hexane solution under the conditions studied.

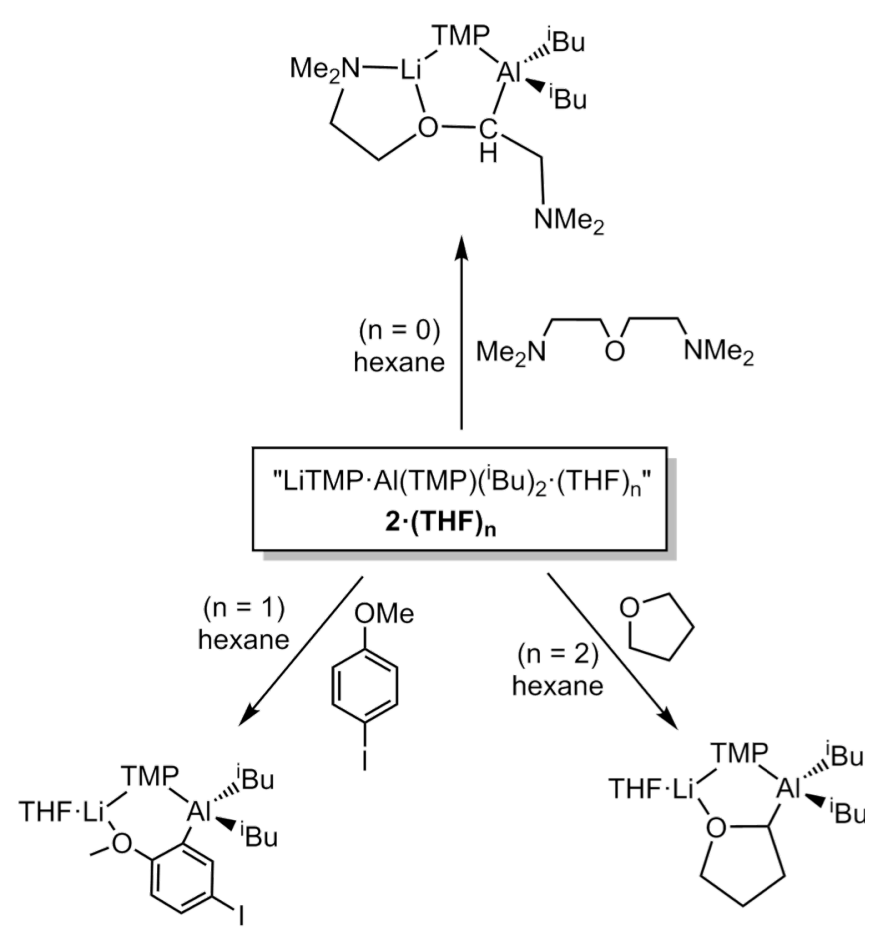

Scheme 3. Selection of deprotonation reactions executed by bis-TMP reagent $\mathbf{2} \cdot(\mathrm{THF})_{n}$.
Since the diamine TMEDA $\left(N, N, N^{\prime}, N^{\prime}-\right.$ tetramethylethylenediamine), the methyl groups of which are only weakly acidic, could also be "aluminated" at one of these terminal methyl sites by in situ $\mathbf{2}$ in hexane solution we originally proposed an intramolecular mechanism through a contacted but open structure as depicted in Scheme $4 .{ }^{30}$ However DFT calculations performed here (see below) indicate that such a twofold TMP structure would be unstable with the Al bound TMP ligand under geometry optimisation moving across to the $\mathrm{Li}$ centre in a non-solvated (TMP)Li( $\mu$ TMP)Al $\left({ }^{\mathrm{i}} \mathrm{Bu}\right)_{2}$ structure which breaks apart to the homometallic components THF $\cdot$ LiTMP ${ }^{31}$ and (TMP)Al $\left({ }^{\mathrm{i}} \mathrm{Bu}\right)_{2}$ on addition of a single THF ligand. It is therefore envisioned that LiTMP does the metallation (lithiation) of TMEDA to give $\mathrm{Li}\left[\mathrm{CH}_{2} \mathrm{~N}(\mathrm{Me}) \mathrm{CH}_{2} \mathrm{CH}_{2} \mathrm{NMe}_{2}\right]$, the reduced steric profile of which compared to that of LiTMP allows its trapping via cocomplexation (trans-metal-trapping is probably more apt here, see later) with carbophilic (TMP)Al $\left({ }^{\mathrm{i}} \mathrm{Bu}\right)_{2}$ to generate the observed heterobimetallic product $\mathrm{Li}\left[\mathrm{CH}_{2} \mathrm{~N}(\mathrm{Me}) \mathrm{CH}_{2} \mathrm{CH}_{2} \mathrm{NMe}_{2}\right]$ (TMP)Al( $\left.{ }^{\mathrm{i}} \mathrm{Bu}\right)_{2}$ (6) (Scheme 4).

If the trans-metal-trapping by the aluminium reagent is not $100 \%$ efficient then lithiated substrates could persist, which might explain the presence of lithiated anisole as well as aluminated anisole in the aforementioned reaction with in situ 1 and anisole (this inefficient trapping was proven directly by mixing lithiated anisole and the salt $\left[\left\{\mathrm{Li}(\mathrm{THF})_{4}\right\}^{+}\left\{\mathrm{Al}\left({ }^{\mathrm{i}} \mathrm{Bu}\right)_{4}\right\}^{-}\right]$, 3 , in $\mathrm{d}_{8}$-THF solution and recording the ${ }^{1} \mathrm{H}$ NMR spectrum which revealed no reaction had taken place - in contrast to the neutral species (TMP)Al $\left({ }^{\mathrm{i}} \mathrm{Bu}\right)_{2}$ which proved an excellent trapping reagent for the lithiated anisole, as detailed below). Applying this same train of thought to the failure of $\mathbf{1} \cdot \mathbf{T H F}$ to likewise metallate anisole in hexane solution can be attributed to the lack of available LiTMP in the reaction mixture as it would be locked within a closed contacted structure with a strong $\operatorname{Li}(\mu-\mathrm{TMP})\left(\mu-{ }^{\mathrm{i}} \mathrm{Bu}\right) \mathrm{Al}$ bridge less sterically congested than an unstable $\operatorname{Li}(\mu \text {-TMP })_{2} \mathrm{Al}$ bridge. Interestingly our initial empirical reasoning that installing two TMP ligands within 2. THF would boost reactivity levels compared to that of the mono-TMP base 1·THF appears correct but for the wrong reason: in no example yet has $\mathbf{2}$ - THF functioned as a di-TMP reacting species, instead it appears to be the "free" LiTMP present in the hexane solution mixture that boosts its reactivity compared to that of $\mathbf{1} \cdot \mathbf{T H F}$. Unlike other bimetallic reagents which can show unusual regioselective orientations, the regioselectivities observed here for $\mathbf{2}$. THF are the same as those found for LiTMP (but in improved yields through the subsequent generation of Al-C bonds which lead to greater stability).

Until the present study no comparable reactivity study of $\mathbf{2}$ had been carried out in bulk THF solution. Therefore we dissolved the components of 2, LiTMP and (TMP)Al( $\left.{ }^{\mathrm{i}} \mathrm{Bu}\right)_{2}$ in THF solution at room temperature and added one molar equivalent of anisole then stirred the mixture for several hours. A ${ }^{1} \mathrm{H}$ NMR spectrum of the reaction mixture in $\mathrm{d}_{6}$-benzene solution confirmed that $\mathbf{2}$, as anticipated, also deprotonates anisole in this bulk polar medium. 


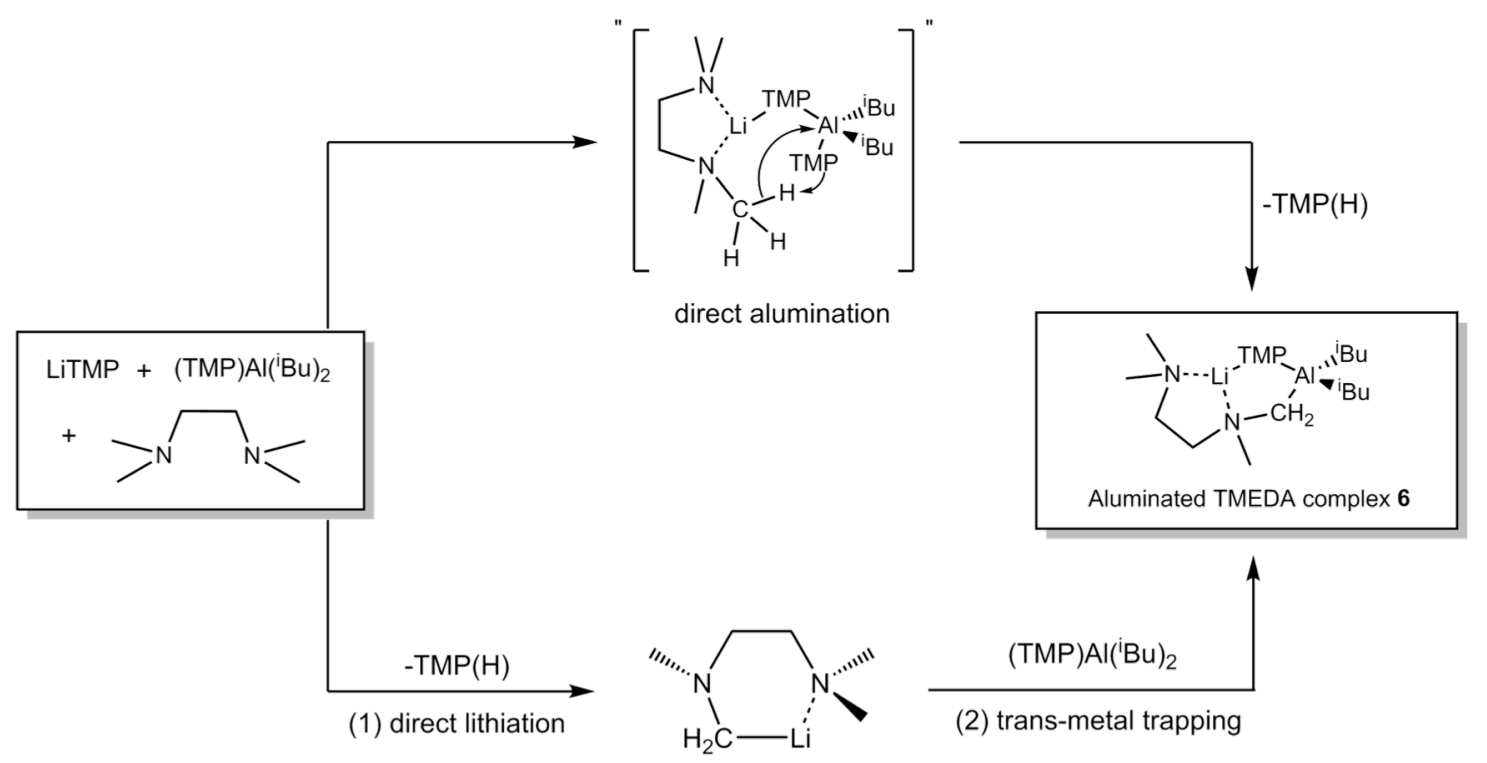

Scheme 4. Previously hypothesised open ring structure pathway for intramolecular AMMA/ reaction of TMEDA (top) and new proposed two-step mechanism for formation of "aluminated" TMEDA complex $\mathrm{Li}\left[\mathrm{CH}_{2} \mathrm{~N}(\mathrm{Me}) \mathrm{CH}_{2} \mathrm{CH}_{2} \mathrm{NMe}_{2}\right]$ (TMP)Al('Bu) ${ }_{2}$ (6) (bottom).

What about the reactivity of 2 in bulk THF solution in the absence of anisole? As mentioned above, previously we established that 2 readily deprotonates a stoichiometric quantity of THF in bulk hexane solution to afford the crystalline THF anion $\left(\mathrm{C}_{4} \mathrm{H}_{7} \mathrm{O}^{-}\right)$contact ion pair complex 4 in a novel example of "cleave and capture chemistry". ${ }^{32}$ Here in this work we allowed 2 on its own to be stirred in THF solution for 24 hours at room temperature before recording a ${ }^{1} \mathrm{H}$ NMR spectrum of the resulting mixture in $\mathrm{d}_{8}$-THF solution. Resonances characteristic of the deprotonated but intact THF ring were observed (e.g., at 2.90, 3.42 and 3.74 ppm, see Figure S14 in ESI) consistent with 4 , but significantly these were only visible on magnifying the spectrum. A substantially larger resonance was seen for $\mathrm{TMP}(\mathrm{H})$ at $1.06 \mathrm{ppm}$, much greater in relative integration terms than could be accounted for by the $\mathrm{TMP}^{-}$ consumed in generating the trace amount of $\mathbf{4}$ witnessed in the spectrum. While hydrolysis can never be ruled out completely as a contributing factor (though we scrupulously dried the THF solvent before employing it in the reaction), it seems more likely that the generated THF anion $\left(\mathrm{C}_{4} \mathrm{H}_{7} \mathrm{O}^{-}\right)$is unstable in the bulk polar medium. It could exist initially either as the lithium derivative $\left[(\mathrm{THF})_{\mathrm{x}}\left(\mathrm{LiOC}_{4} \mathrm{H}_{7}\right)_{\mathrm{n}}\right]$ or the solvent-separated aluminate $\left[\left\{\mathrm{Li}(\mathrm{THF})_{4}\right\}^{+}\left\{(\mathrm{TMP})\left(\mathrm{OC}_{4} \mathrm{H}_{7}\right) \mathrm{Al}\left({ }^{\mathrm{i}} \mathrm{Bu}\right)_{2}\right\}^{-}\right]$(contrast this with the bimetallic-stabilised contacted ion pair form 4 found in hexane solution $)^{29}$ but would then decompose presumably via a $[3+2]$ cycloreversion to the enolate of acetaldehyde and ethene (Scheme 5). ${ }^{33}$ To investigate what effect this formation and break down of $\mathbf{4}$ would exert on the Brønsted basic properties of $\mathbf{2}$ we stirred a THF solution of $\mathbf{2}$ for 24 hours before introducing anisole as the metallation probe. As expected no metallation of anisole took place as a ${ }^{1} \mathrm{H}$ NMR spectrum of the reaction mixture revealed free anisole as well as THF anions and a substantial amount of TMP(H). From these observations we conclude that if left to stir for a period of time in THF solution, 2 will deprotonate THF releasing $\mathrm{TMP}(\mathrm{H})$ and be consumed. To check whether all base activity is lost under such circumstances, we crystallised $\mathbf{4}$ from hexane solution, isolated it and dissolved it in bulk THF solution. Anisole was added subsequently and the solution was stirred for 24 hours. NMR analysis of the resulting mixture revealed that again no metallation of anisole had occurred confirming that aluminate 4 , probably present in the modified solventseparated form $\left[\left\{\mathrm{Li}(\mathrm{THF})_{4}\right\}^{+}\left\{(\mathrm{TMP})\left(\mathrm{OC}_{4} \mathrm{H}_{7}\right) \mathrm{Al}\left({ }^{\mathrm{i}} \mathrm{Bu}\right)_{2}\right\}^{-}\right]$is inactive as a base even though it contains a TMP ligand.

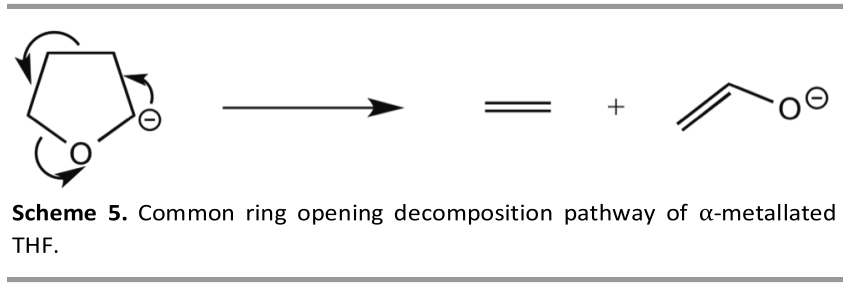

Curious about the constitution of $\mathbf{2}$ in THF solution we compared its ${ }^{1} \mathrm{H}$ NMR spectrum with those of its constituent parts LiTMP and (TMP)Al $\left({ }^{\mathrm{i}} \mathrm{Bu}\right)_{2}$ (see composite spectra in Figure 5). Close examination of these spectra show that the principal resonances of LiTMP (Me of TMP at $1.07 \mathrm{ppm}$ ) and (TMP)Al $\left({ }^{\mathrm{i}} \mathrm{Bu}\right)_{2}$ (Me of TMP at $1.21 \mathrm{ppm} ; \mathrm{CH}_{2}$ of ${ }^{\mathrm{i}} \mathrm{Bu}$ at 0.03 ppm) match almost exactly with corresponding resonances in 2 $(1.04,1.21$ and $0.03 \mathrm{ppm}$, respectively) though it is noticeable that the resonances associated with LiTMP are extremely sensitive to even small changes in concentration. Therefore it appears certain that under the conditions studied [longer periods of time lead to the deprotonation/decomposition of THF] LiTMP and (TMP)Al $\left({ }^{\mathrm{i}} \mathrm{Bu}\right)_{2}$ exist as separate species each solvated by THF. This viewpoint is supported by a DOSY spectrum, which shows a significant difference in the diffusion 


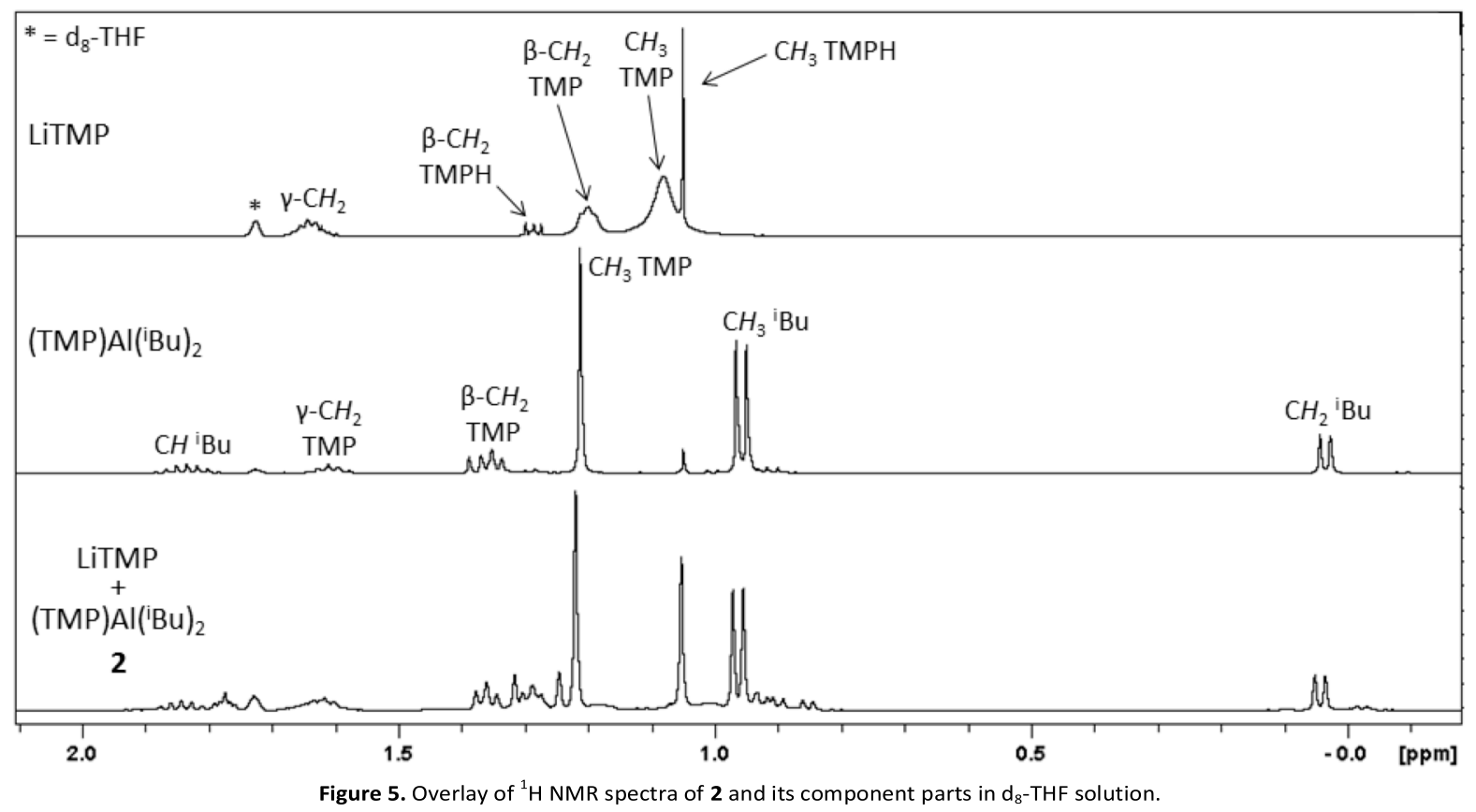

coefficients for each compound [LiTMP $=1.22 \times 10^{-9} \mathrm{~m}^{2} / \mathrm{s}$; (TMP)Al $\left.\left({ }^{\mathrm{i}} \mathrm{Bu}\right)_{2}=8.37 \times 10^{-10} \mathrm{~m}^{2} / \mathrm{s}\right]$. Thus clearly whether in hexane or THF solution there is no interaction between LiTMP and (TMP)Al( $\left({ }^{\mathrm{i}} \mathrm{Bu}\right)_{2}$ due to a formidable steric barrier, but once LiTMP metallates a substrate (e.g., THF or anisole) the new lithiated substrate species being of reduced steric profile and greater nucleophilicity through Li-C bond formation can join together (be trapped) with the neutral aluminium complex. Evidence that such fragments can join together comes from the previously reported crystal structures of $[(\mathrm{THF}) \cdot \mathrm{Li}(\mu-\mathrm{TMP})(\mu-$ $\left.\left.\mathrm{OC}_{4} \mathrm{H}_{7}\right) \mathrm{Al}\left({ }^{\mathrm{i}} \mathrm{Bu}\right)_{2}\right], \quad 4^{29}$ and $[(\mathrm{THF}) \cdot \mathrm{Li}(\mu-\mathrm{TMP})(o-$ $\left.\left.\mathrm{C}_{6} \mathrm{H}_{4} \mathrm{OMe}\right) \mathrm{Al}\left({ }^{\mathrm{i}} \mathrm{Bu}\right)_{2}\right], 5,{ }^{12}$ respectively (see also the DFT study detailed below).

Taking stock of these findings the picture of $\mathbf{2}$ in bulk THF solution emerging now is that only LiTMP (solvated by THF), (TMP)Al( $\left.{ }^{\mathrm{i}} \mathrm{Bu}\right)_{2}$ (solvated by THF), and depending on the age and history of the solution variable amounts of the THF degradation products 4 (presumably in its THF-separated form $\left.\left[\left\{\mathrm{Li}(\mathrm{THF})_{4}\right\}^{+}\left\{\left(\mathrm{OC}_{4} \mathrm{H}_{7}\right)(\mathrm{TMP}) \mathrm{Al}\left({ }^{\mathrm{i}} \mathrm{Bu}\right)_{2}\right\}^{-}\right]\right)$,

$\left[(\mathrm{THF})_{\mathrm{x}}\left(\mathrm{LiOC}_{4} \mathrm{H}_{7}\right)_{\mathrm{n}}\right],\left[(\mathrm{THF})_{\mathrm{n}} \mathrm{LiO}-\mathrm{C}=\mathrm{CH}_{2}\right]^{34}$ and ethene are observable by this NMR spectroscopic interrogation. Significantly we can find no evidence for a bimetallic cocomplex "LiTMP-Al(TMP $)\left({ }^{\mathrm{i}} \mathrm{Bu}\right)_{2}$ " 2 which falls into line with our DFT computational analysis (see below) that questions the thermodynamic feasibility of such a di-TMP contacted or solvent-separated bimetallic structure.

Having tested all of the metal species within this $\mathbf{2}$ mixture for their metallating ability the only possible candidate to emerge is the aforementioned LiTMP, which in bulk THF solution exists in solvated form as deduced by Renaud and Fox who observed both dimeric and monomeric forms through ${ }^{7} \mathrm{Li}$ NMR spectroscopic studies. ${ }^{35}$ Wheatley et al confirmed these assignments in a later paper. ${ }^{11 \mathrm{~b}}$

To establish whether LiTMP was the active Brønsted base component in 2 we dissolved freshly prepared LiTMP in $\mathrm{d}_{6^{-}}$ benzene solution in an NMR tube to which a few drops of THF were added. A ${ }^{1} \mathrm{H}$ NMR spectrum of this mixture was recorded after 30 minutes and again after 24 hours (see Figure S17 in ESI). Ethene was revealed in both spectra through a resonance at $5.25 \mathrm{ppm}$, which increased with time, consistent with the metallation, ring opening and cleavage of THF. Significantly when 2 is left to stir in bulk THF solution for 24 hours a small amount of aluminate $\mathbf{4}$ is observed as mentioned previously, the implication being that LiTMP is lithiating THF to generate " $\mathrm{C}_{4} \mathrm{H}_{7} \mathrm{O}^{-}$" anions a small amount of which is trapped by (TMP)Al $\left({ }^{\mathrm{i}} \mathrm{Bu}\right)_{2}$ to generate $\left[\left(\mathrm{OC}_{4} \mathrm{H}_{7}\right)(\mathrm{TMP}) \mathrm{Al}\left({ }^{\mathrm{i}} \mathrm{Bu}\right)_{2}\right]^{-}$while the remainder decompose to ethene and lithium enolate. We also examined the lithiation of anisole (Scheme 6). Uchiyama, Mongin et al previously reported that subjecting anisole to one molar equivalent of LiTMP in THF solution over two hours produced after iodine quenching only $9 \%$ of orthoiodoanisole. ${ }^{36}$ To ascertain how much lithiated anisole was present prior to any quenching step we reacted LiTMP with anisole in the same stoichiometry in THF solution, but found the reaction afforded only about a $5 \%$ yield of lithiated anisole. Hence LiTMP can definitely metallate/lithiate anisole, unlike any of the other species identified within the mixture of $\mathbf{2}$, albeit in a meagre yield. Since 2 furnishes excellent yields of metallated anisole following iodine quenching the implication is that once formed any lithiated anisole will be quickly trapped by the strongly carbophilic (TMP)Al $\left({ }^{\mathrm{i}} \mathrm{Bu}\right)_{2}$. This was established unequivocally by taking a 1:1 mixture of lithiated anisole (prepared separately by reaction of anisole and ${ }^{t} \mathrm{BuLi}$ in 


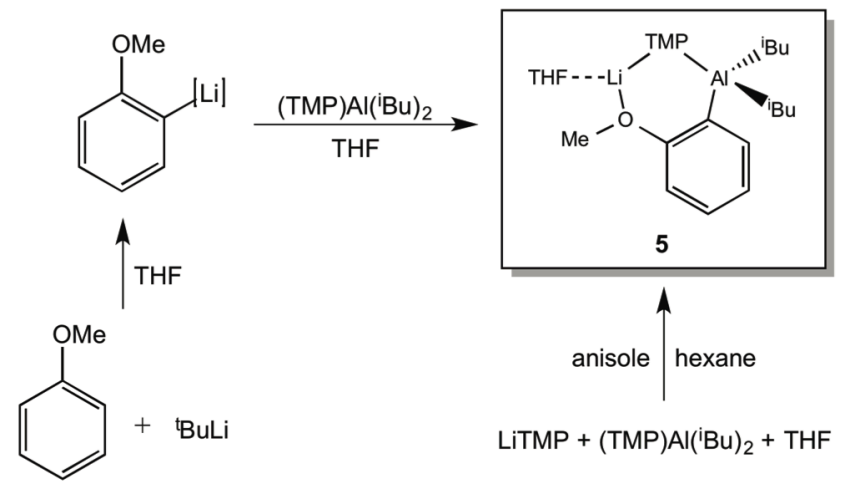

Scheme 6. Capture of "aluminated" anisole by direct (RHS) and indirect (LHS) approaches.

THF at $\left.0{ }^{\circ} \mathrm{C}\right)^{37}$ and (TMP)Al $\left({ }^{\mathrm{i}} \mathrm{Bu}\right)_{2}$ in $\mathrm{d}_{8}$-THF solution in an NMR tube and recording the ${ }^{1} \mathrm{H}$ and ${ }^{13} \mathrm{C}$ spectra (see Figures $\mathrm{S} 11$ and $\mathrm{S} 12$ in ESI). The most diagnostic resonance in the former, the meta $\mathrm{C}-\mathrm{H}$ adjacent to the metallated $\mathrm{C}-\mathrm{M}$, shows a significant upfield shift (from 7.66 to $7.49 \mathrm{ppm}$ ) signifying the attached metal $\mathrm{M}$ has switched from $\mathrm{Li}$ to $\mathrm{Al}$; with a similar shift seen in the ${ }^{13} \mathrm{C}$ spectra for the metallated $C$-M atom from 159.2 to $154.4 \mathrm{ppm}$ [note that Uchiyama reported a similar but not identical upfield Li to Al shift on treating lithiated anisole with ${ }^{\mathrm{t}} \mathrm{BuLi}$ with the $\mathrm{C}-\mathrm{Al}$ resonance appearing at $152.91 \mathrm{ppm}$, the main distinction being the trapping $\mathrm{Al}$ reagent used was $\left.\mathrm{Al}\left({ }^{\mathrm{i}} \mathrm{Bu}\right)_{3}\right]$. From integration ratios this trans-metal trapping of the anisolyl carbanion by (TMP)Al $\left({ }^{\mathrm{i}} \mathrm{Bu}\right)_{2}$ seems essentially quantitative. As depicted in Scheme 7, this insertion of the aluminium reagent into the $\mathrm{Li}-\mathrm{C}$ (anisolyl) bond should drive the equilibrium between anisole and lithiated anisole towards the lithiated species thus increasing the overall metallation yield of the reaction. We established that such an equilibrium exists between lithiated anisole and LiTMP by taking a freshly prepared sample of the former and mixing it with an equimolar amount of $\mathrm{TMP}(\mathrm{H})$ in $\mathrm{d}_{6}$-benzene solution and stirring the solution for 10 minutes. At this point LiTMP was observed via a ${ }^{1} \mathrm{H}$ NMR spectrum. It is worthy of comment that (TMP)Al $\left({ }^{\mathrm{i}} \mathrm{Bu}\right)_{2}$, though not a metallating agent itself, contributes to the success of the metallation reactions of $\mathbf{2}$ in two key ways: firstly, it traps the lithium carbanion and stabilises the carbanion moiety by reducing the polarity of the metal-carbon bond; secondly, by not engaging at all with LiTMP on the left hand side of the equation (Scheme 7) the equilibrium can shift towards the desired anisolyl aluminium product. This hypothesis of non-cocomplexed LiTMP and (TMP)Al $\left({ }^{\mathrm{i}} \mathrm{Bu}\right)_{2}$ homometallic species swimming separately in a pool of THF runs counter to any thinking that a "LiTMP-Al(TMP) $\left({ }^{\mathrm{i}} \mathrm{Bu}\right)_{2}$ " cocomplex was responsible for these "AMMAl" reactions. Therefore the weight of evidence from this work suggests these reactions are not in fact direct aluminations (aluminium-hydrogen exchanges) at all but rather two step lithiation/trans-metal-trapping processes (trans-metaltrapping seems a more apt description here than the usual applied "transmetallation" for although aluminium is replacing

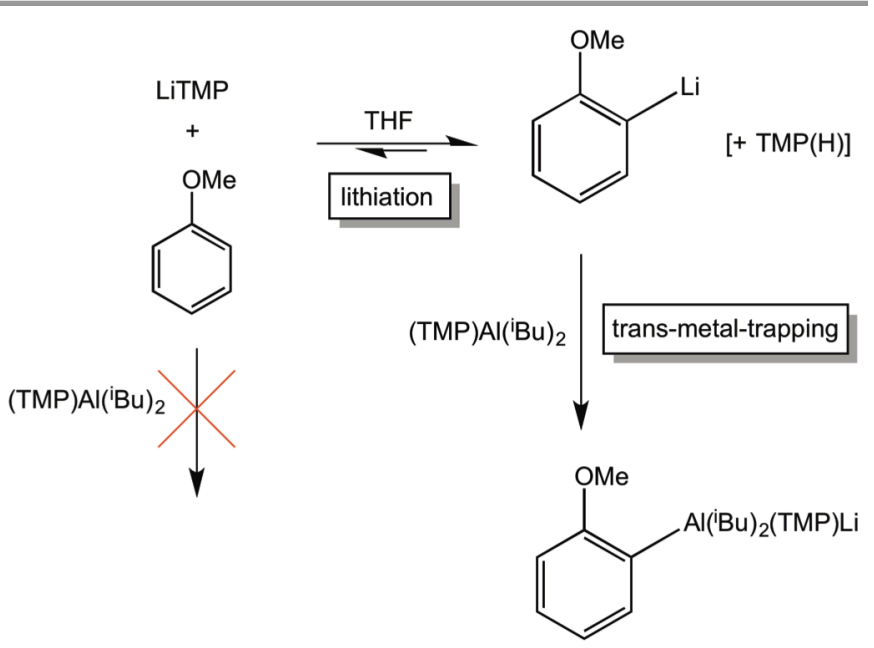

Scheme 7. Proposed two-step pathway for the "alumination" of anisole.

lithium in binding to the carbanion $\mathrm{C}$ atom the lithium may not necessarily leave the aluminium system but could remain part of a contacted ion pair or solvent separated ion pair compound). Similar reactivities to this one have recently been reported for the homoleptic bimetallic mixtures of LiTMP and $\mathrm{Zn}(\mathrm{TMP})_{2}{ }^{38}$ or $\mathrm{Cd}(\mathrm{TMP})_{2}{ }^{39}$ as they appear not to be "LiZn(TMP) $)_{3}$ " or "LiCd(TMP) $)_{3}$ " tris-TMP ates, but instead remain separated components in which LiTMP is also the active metallating base. ${ }^{9,40}$

Despite this evaluation of the reactions of $\mathbf{2}$ in bulk THF solutions not being AMMAls the essential point remains the same that these reactions are still synergistic in origin (for efficiency but not for any special selectivity) for without participation of the aluminium reagent, quenching of the lithiated substrates with electrophiles $\mathrm{E}^{+}$would be unsatisfactory leading to poor yields of the desired $\mathrm{E}^{+}$(substrate) ${ }^{-}$products. This reflects the non-selective nature of iodine quenching as it would quench both lithiated anisole and LiTMP to prevent the equilibrium in Scheme 7 shifting towards lithiated anisole; whereas the aluminium reagent selectively targets lithiated anisole and ignores the bulkier LiTMP.

\section{Re-evaluating the composition and active base component of in situ 1 in THF solution.}

Now that the picture of $\mathbf{2}$ in THF solution is much more transparent following these new findings, the composition of $\mathbf{1}$ in THF solution needs to be re-considered. Taking into account the surprising discovery that LiTMP is the active base component within $\mathbf{2}$ we can propose a more complete composition for $\mathbf{1}$ (Scheme 8). Far removed from the original idea that it existed as a single species of formula $\left[(\mathrm{THF}) \cdot \mathrm{Li}(\mathrm{TMP})\left({ }^{\mathrm{i}} \mathrm{Bu}\right) \mathrm{Al}\left({ }^{\mathrm{i}} \mathrm{Bu}\right)_{2}\right]$, in this proposal $\mathbf{1}$ contains no less than five species in two interconnected equilibria including most significantly the separated monometallic species LiTMP, which we have already established can perform metallation of a substrate. Convincing evidence for the second equilibrium came from mixing authentic samples of the salt $\left[\left\{\mathrm{Li}(\mathrm{THF})_{4}\right\}^{+}\left\{\mathrm{Al}\left({ }^{\mathrm{i}} \mathrm{Bu}\right)_{4}\right\}^{-}\right], \quad 3$, and (TMP) $\mathrm{Al}\left({ }^{\mathrm{i}} \mathrm{Bu}\right)_{2}$ in $\mathrm{d}_{8}-\mathrm{THF}$ 


\title{
$\mathrm{LiTMP}+\mathrm{Al}\left({ }^{\mathrm{i} B \mathrm{Bu}}\right)_{3} \stackrel{\mathrm{THF}}{\rightleftharpoons}\left[\left\{\mathrm{Li}(\mathrm{THF})_{4}\right\}^{+}\left\{\mathrm{Al}(\mathrm{TMP})(\mathrm{Bu})_{3}\right\}^{-}\right]$ $1 \cdot(\mathrm{THF})_{4}$
}

\author{
$\mathrm{Al}\left({ }^{(\mathrm{Bu}}\right)_{3}+\left[\left\{\mathrm{Li}(\mathrm{THF})_{4}\right\}^{+}\left\{\mathrm{Al}(\mathrm{TMP})\left({ }^{\mathrm{i}} \mathrm{Bu}\right)_{3}\right\}^{-}\right] \stackrel{\mathrm{THF}}{\rightleftharpoons}\left[\left\{\mathrm{Li}(\mathrm{THF})_{4}\right\}^{+}\left\{\mathrm{Al}\left({ }^{\mathrm{i}} \mathrm{Bu}\right)_{4}\right\}^{-}\right]+(\mathrm{TMP}) \mathrm{Al}(\mathrm{i} \mathrm{Bu})_{2}$ \\ $\mathbf{1} \cdot(\mathrm{THF})_{4}$ \\ 3
}

Scheme 8. Re-evaluated composition of "single-species" THF-Li(TMP)·Al('Bu) ${ }_{3}$ showing its existence as two connected equilibria involving five distinct species.

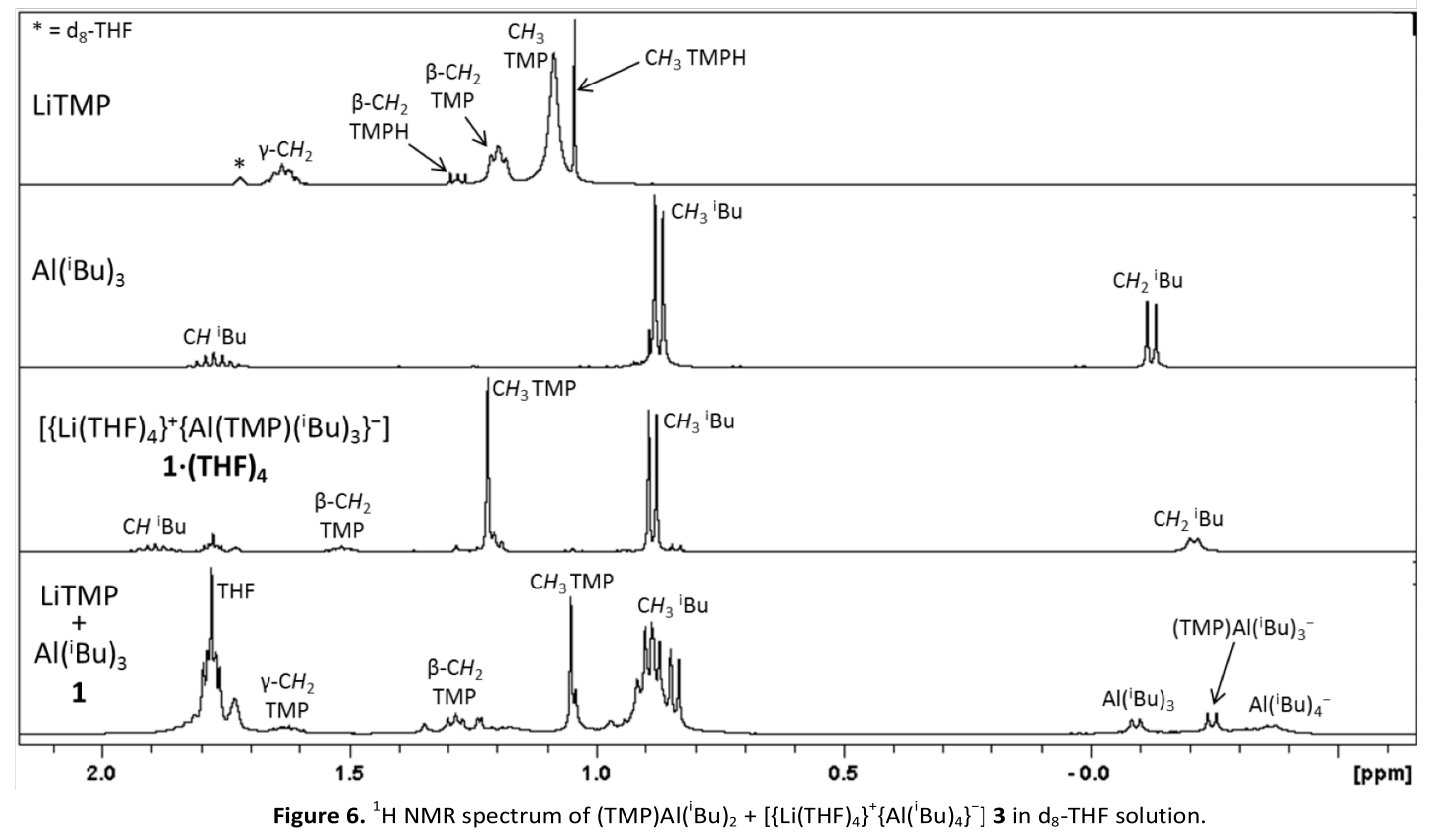

solution and recording the ${ }^{1} \mathrm{H}$ NMR spectrum at room temperature (Figure 6). The low frequency region about $0 \mathrm{ppm}$ is extremely informative as each species exhibits a well-defined Al- $\mathrm{CH}_{2}\left({ }^{\mathrm{i}} \mathrm{Bu}\right)$ resonance within it. Four such resonances observed at $(0.02,-0.10,-0.22$ and $-0.37 \mathrm{ppm})$ can be assigned to (TMP)Al $\left({ }^{\mathrm{i}} \mathrm{Bu}\right)_{2}, \mathrm{Al}\left({ }^{\mathrm{i}} \mathrm{Bu}\right)_{3},\left[\left\{\mathrm{Li}(\mathrm{THF})_{4}\right\}^{+}\left\{\mathrm{Al}(\mathrm{TMP})\left({ }^{\mathrm{i}} \mathrm{Bu}\right)_{3}\right\}^{-}\right]$ and $\left[\left\{\mathrm{Li}(\mathrm{THF})_{4}\right\}^{+}\left\{\mathrm{Al}\left({ }^{\mathrm{i}} \mathrm{Bu}\right)_{4}\right\}^{-}\right]$respectively. Four $\mathrm{CH}_{3}\left({ }^{\mathrm{i}} \mathrm{Bu}\right)$ resonances were also observed for the four distinct species though the doublet of doublets for $\mathrm{Al}\left({ }^{\mathrm{i}} \mathrm{Bu}\right)_{3}$ and $\left[\left\{\mathrm{Li}(\mathrm{THF})_{4}\right\}^{+}\left\{\mathrm{Al}(\mathrm{TMP})\left({ }^{\mathrm{i}} \mathrm{Bu}\right)_{3}\right\}^{-}\right]$overlap. All assignments were verified by comparison with the spectra of authentic samples of the individual components. The trialkyl-amido aluminate $\left[\left\{\mathrm{Li}(\mathrm{THF})_{4}\right\}^{+}\left\{\mathrm{Al}(\mathrm{TMP})\left({ }^{\mathrm{i}} \mathrm{Bu}\right)_{3}\right\}^{-}\right]$was prepared by reacting neutral (TMP)Al $\left({ }^{\mathrm{i}} \mathrm{Bu}\right)_{2}$ with an equimolar amount of ${ }^{\mathrm{i}} \mathrm{BuLi}$ in THF solution (Figures S20 and S21 in ESI, note the corresponding resonance for ${ }^{\mathrm{i}} \mathrm{BuLi}$ comes more upfield at -0.98 $\mathrm{ppm}$ ) and this aluminate gave an identical spectrum to that of crystalline 1-THF dissolved in $d_{8}$-THF solution, which we discovered was inactive as a base. It is also significant that no LiTMP was found in the spectrum of the $\left[\left\{\mathrm{Li}(\mathrm{THF})_{4}\right\}^{+}\left\{\mathrm{Al}\left({ }^{\mathrm{i}} \mathrm{Bu}\right)_{4}\right\}^{-}\right], 3$, and (TMP)Al $\left({ }^{\mathrm{i}} \mathrm{Bu}\right)_{2}$ mixture as evidenced by the absence of a Me resonance at $1.05 \mathrm{ppm}$. When
TMP is attached to Al this Me resonance moves downfield to $1.21 \mathrm{ppm}$ in (TMP)Al( $\left.{ }^{\mathrm{i}} \mathrm{Bu}\right)_{2}$ and $1.20 \mathrm{ppm}$ in $\left[\left\{\mathrm{Li}(\mathrm{THF})_{4}\right\}^{+}\left\{\mathrm{Al}(\mathrm{TMP})\left({ }^{\mathrm{i}} \mathrm{Bu}\right)_{3}\right\}^{-}\right]$though these signals cannot be differentiated in the combined spectrum. Since the equilibrium under these ambient temperature conditions greatly favours (TMP)Al $\left({ }^{\mathrm{i}} \mathrm{Bu}\right)_{2}$ its $\mathrm{Me}(\mathrm{TMP})$ resonance is much larger than that of $\left[\left\{\mathrm{Li}(\mathrm{THF})_{4}\right\}^{+}\left\{\mathrm{Al}(\mathrm{TMP})\left({ }^{\mathrm{i}} \mathrm{Bu}\right)_{3}\right\}^{-}\right]$. Measurement of the relative integrals of $\left[\left\{\mathrm{Li}(\mathrm{THF})_{4}\right\}^{+}\left\{\mathrm{Al}(\mathrm{TMP})\left({ }^{\mathrm{i}} \mathrm{Bu}\right)_{3}\right\}^{-}\right]$and $\mathrm{Al}\left({ }^{\mathrm{i}} \mathrm{Bu}\right)_{3}$ is hampered by the broadness of the $\mathrm{Al}-\mathrm{CH}_{2}\left({ }^{\mathrm{i}} \mathrm{Bu}\right)$ resonance of the former species. Note that the corresponding resonance for the homoleptic ate $\left[\left\{\mathrm{Li}(\mathrm{THF})_{4}\right\}^{+}\left\{\mathrm{Al}\left({ }^{\mathrm{i}} \mathrm{Bu}\right)_{4}\right\}^{-}\right]$is similarly broad. ${ }^{21}$ In both cases the broadness can be attributed to the quadrupolar effect of the ${ }^{27} \mathrm{Al}$ centre (spin 5/2). In the symmetrical species $\left[\left\{\mathrm{Li}(\mathrm{THF})_{4}\right\}^{+}\left\{\mathrm{Al}\left({ }^{\mathrm{i}} \mathrm{Bu}\right)_{4}\right\}^{-}\right]$the $\mathrm{Al}-\mathrm{CH}_{2}$ $\left({ }^{\mathrm{i}} \mathrm{Bu}\right)$ resonance is a doublet due to coupling with the adjacent $\mathrm{CH}$ but this is further split by the Al into a doublet of sextets though as the environment is not perfectly symmetrical some merging of the lines occurs and the resonance observed appears wide and broad (see Figures S24 and S25 in the ESI for decoupling and 2D $\left[{ }^{1} \mathrm{H},{ }^{27} \mathrm{Al}\right] \mathrm{HSQC}$ and HSQC-TOCSY experiments which support the $\mathrm{Al}$ and ${ }^{\mathrm{I}} \mathrm{Bu}$ assignments within $\mathbf{1} \cdot(\mathbf{T H F})_{4}$ and 3 ). The equilibria are also implicated on mixing 


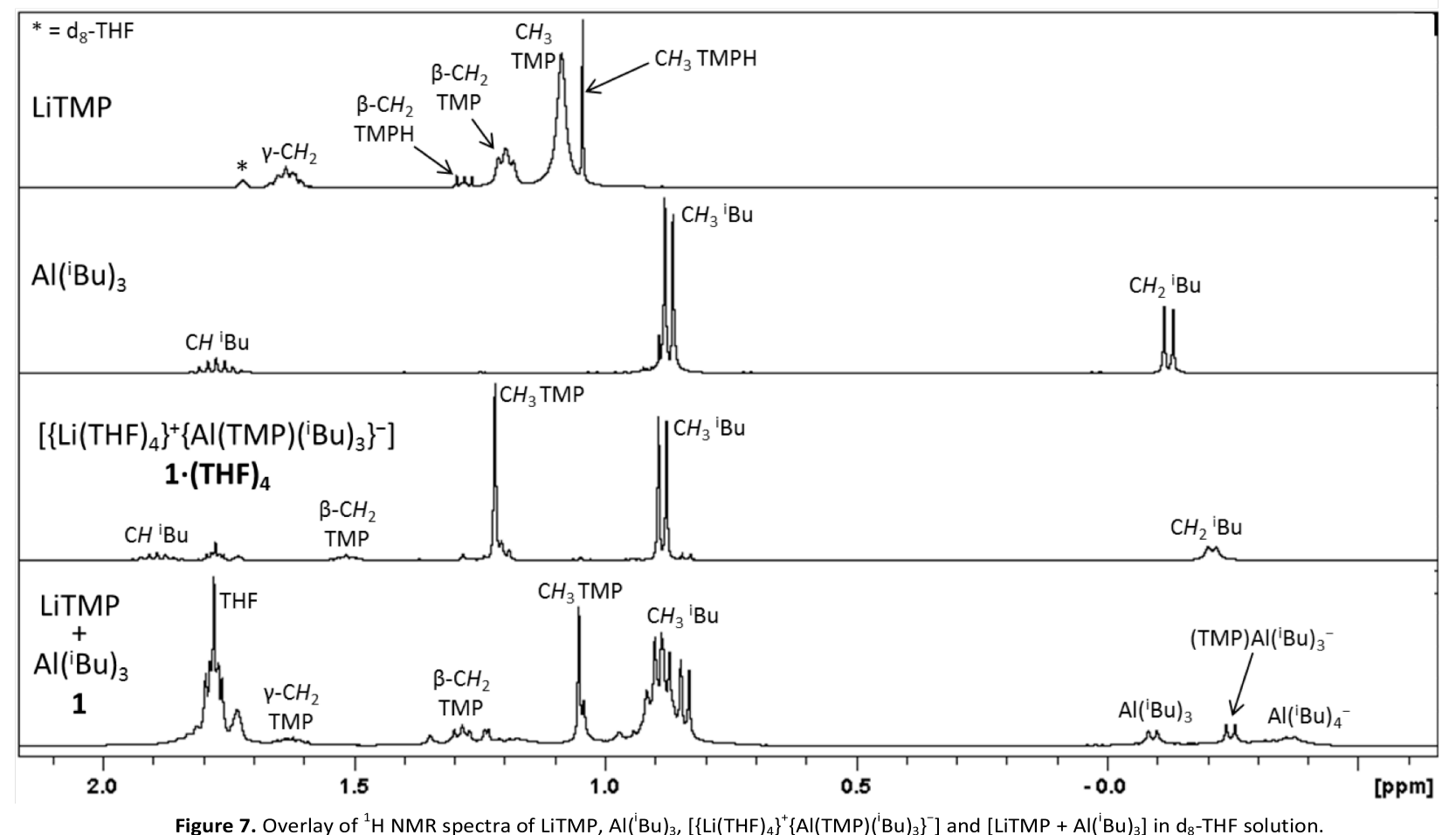

equimolar proportions of LiTMP and $\mathrm{Al}\left({ }^{\mathrm{i}} \mathrm{Bu}\right)_{3}$ in $\mathrm{d}_{8}$-THF solution (see the spectra comparison in Figure 7). On recording this ${ }^{1} \mathrm{H}$ NMR spectrum at $0{ }^{\circ} \mathrm{C}$, the resonances for LiTMP (most diagnostically the Me resonance at $1.05 \mathrm{ppm}$, though this overlaps with a TMPH resonance the presence of which is unavoidable due to attack of THF by LiTMP) and $\mathrm{Al}\left({ }^{\mathrm{i}} \mathrm{Bu}\right)_{3}$ (at $0.25 \mathrm{ppm}$ ) are the most prominent. A smaller extremely broad resonance for $\left[\left\{\mathrm{Li}(\mathrm{THF})_{4}\right\}^{+}\left\{\mathrm{Al}\left({ }^{\mathrm{i}} \mathrm{Bu}\right)_{4}\right\}^{-}\right]$is clearly seen too. The presence of $\left[\left\{\mathrm{Li}(\mathrm{THF})_{4}\right\}^{+}\left\{\mathrm{Al}\left({ }^{\mathrm{i}} \mathrm{Bu}\right)_{4}\right\}^{-}\right]$is also clearly distinguishable in the Me region of the ${ }^{\mathrm{i}} \mathrm{Bu}$ group as a doublet at $0.84 \mathrm{ppm}$, though the analogous doublets for the other ${ }^{\mathrm{i}} \mathrm{Bu}$ containing species overlap into a complex multiplet at about $0.89 \mathrm{ppm}$ consistent with there being multiple species present rather than simply $\mathrm{Al}\left({ }^{\mathrm{i}} \mathrm{Bu}\right)_{3}$. Due to the fact that we are seeing some metallation in the solution due to the presence of TMPH then it is possible that the amount of (TMP) $\mathrm{Al}\left({ }^{\mathrm{i}} \mathrm{Bu}\right)_{2}$ in solution is being decreased as this species will trap any carbanion formed upon metallation (see earlier discussion of efficient trapping of anisolyl anions by (TMP) $\left.\mathrm{Al}\left({ }^{\mathrm{i}} \mathrm{Bu}\right)_{2}\right)$. Clearly the $\left({ }^{\mathrm{i}} \mathrm{Bu}\right) \mathrm{Me}$ region at $0.80-0.95 \mathrm{ppm}$ in containing more than the four overlapping species you would expect in the equilibrium proposed supports this suggestion. Other ates of formula (TMP) $\mathrm{Al}\left({ }^{\mathrm{i}} \mathrm{Bu}\right)_{2} \mathrm{X}$ where $\mathrm{X}$ is for example $\mathrm{C}_{4} \mathrm{H}_{7} \mathrm{O}^{-}$or $\mathrm{C}_{2} \mathrm{H}_{3} \mathrm{O}^{-}$ formula could also be present. To check whether LiTMP was participating in an equilibrium with the salt $\left[\left\{\mathrm{Li}(\mathrm{THF})_{4}\right\}^{+}\left\{\mathrm{Al}\left({ }^{\mathrm{i}} \mathrm{Bu}\right)_{4}\right\}^{-}\right]$we added both to a $\mathrm{d}_{8}$-THF solution and monitored it by ${ }^{1} \mathrm{H}$ NMR spectroscopy. The spectra revealed that the resonances associated with the two individual compounds remain unchanged. We thus conclude that these two species are not in equilibrium with each other. Neither is LiTMP in equilibrium with (TMP)Al $\left({ }^{\mathrm{i}} \mathrm{Bu}\right)_{2}$ as we established through the aforementioned studies of $\mathbf{2} \cdot \mathbf{T H F}$.

Based on these new observations we can find no evidence at all for a species of composition " $\left[\left\{\mathrm{Li}(\mathrm{THF})_{\mathrm{n}}\right\}^{+}\left\{\mathrm{Al}(\mathrm{TMP})_{2}\left({ }^{\mathrm{i}} \mathrm{Bu}\right)_{2}\right\}^{-}\right] "$ that we had originally presumed in the dismutation process shown in Scheme 2. DFT calculations (see below) support the non-existence of such a heteroleptic aluminate species. It transpires that $\mathbf{1} \cdot \mathbf{T H F}$ is much more complicated existing in at least five distinct species in THF solution. The complexity can be attributed to the lability of $\mathrm{Al}\left({ }^{\mathrm{i}} \mathrm{Bu}\right)_{3}$ which can add a TMP ligand to generate $\left[\left\{(\mathrm{TMP}) \mathrm{Al}\left({ }^{\mathrm{i}} \mathrm{Bu}\right)_{3}\right\}^{-}\right]$and gain or lose an ${ }^{\mathrm{i}} \mathrm{Bu}$ group to form $\left[\mathrm{Al}\left({ }^{\mathrm{i}} \mathrm{Bu}\right)_{4}{ }^{-}\right]$or $\left[\mathrm{Al}\left({ }^{\mathrm{i}} \mathrm{Bu}\right)_{2}{ }^{+}\right]$containing species; whereas by comparison the solution chemistry of $\mathbf{2}$. THF is much simpler due to the relative poor lability of (TMP) $\mathrm{Al}\left({ }^{\mathrm{i}} \mathrm{Bu}\right)_{2}$ and specifically its inability to form a co-complex with LiTMP on steric grounds. Where $\mathbf{1} \cdot \mathbf{T H F}$ and $\mathbf{2} \cdot \mathbf{T H F}$ do coincide is in the fact that the active base ingredient in both mixtures in THF solution is LiTMP. Ironically, revisiting the original question, "has the active base of $\mathbf{1}$ been crystallographically characterised?", the revised answer is yes, as LiTMP has been crystallographically characterised in two different polymorphic forms ${ }^{26}$ as well as in a THF-solvated form. ${ }^{31} \mathbf{2} \cdot \mathbf{T H F}$ is the strongest base because it would always have the largest proportion of LiTMP present in a solution of the same molarity; whereas in 1.THF some LiTMP will always be lost due to the equilibria in operation. This last point is in agreement with the excess of 1 THF (2.2 molar equivalents) used by Uchiyama et 
al in their synthetic applications to ensure maximum yields of the metallated/quenched substrates were obtained. Moreover 1.THF is never going to be a good base in hexane solution for if the LiTMP: $\mathrm{Al}\left({ }^{\mathrm{i}} \mathrm{Bu}\right)_{3}$ ratio in the starting mixture is exactly $1: 1$ there will be no free LiTMP available to perform the metallation. However, there are at least two qualifications. First, at higher temperatures the contacted ion pair structure of 1. THF could break up and release LiTMP making metallations of suitably thermally stable substrates a possibility. In contrast free LiTMP is always available in hexane solutions of $\mathbf{2}$. THF. Second, Lewis bases can coordinate to the Lewis acidic lithium centre and generate a contacted ion pair aluminate with $\mathrm{Al}\left({ }^{\mathrm{i}} \mathrm{Bu}\right)_{3}$ that can subsequently metallate a $\mathrm{C}-\mathrm{H}$ bond in the Lewis base in a genuine example of alkali-metal-mediated alumination. This possibility has already been demonstrated in the formation of $\left[\mathrm{Li}\left\{\mathrm{Me}_{2} \mathrm{NCH}_{2} \mathrm{CH}_{2} \mathrm{~N}(\mathrm{Me}) \mathrm{CH}_{2}\right\}_{2} \mathrm{Al}\left({ }^{\mathrm{i}} \mathrm{Bu}\right)_{2}\right]$ (6) by reaction of 1 with two equivalents of TMEDA in hexane solution. ${ }^{30}$

\section{DFT Calculations}

\section{Theoretical calculations}

The structure of $\mathbf{1}$ "LiTMP.Al $\left({ }^{\mathrm{i}} \mathrm{Bu}\right)_{3}$ " was previously interrogated by DFT calculations using the B3LYP/6-31+G* level of theory. ${ }^{11 \mathrm{~b}}$ This comprehensive theoretical study by Naka, Uchiyama, and Wheatley et al was performed on $\left[\mathrm{S} \cdot \mathrm{LiNMe}_{2} \cdot \mathrm{Al}(\mathrm{Me})_{3}\right]$ (where $\mathrm{S}=$ the donor solvent $\mathrm{Me}_{2} \mathrm{O}$ ) for calculational simplicity and its metallation reaction with anisole was modelled. Rigorous in its detail and broad in scope, this study uncovered possible intermediates and transition states along the reaction coordinate as well as quantifying the energy differences involved. However, its starting point of a contacted ion pair structure $\left[\mathrm{S} \cdot \mathrm{Li}(\mu-\mathrm{Me})\left(\mu-\mathrm{NMe}_{2}\right) \cdot \mathrm{Al}(\mathrm{Me})_{2}\right]$ and the subsequent pre-metallation complex it forms with anisole $\left[\mathrm{Ph}(\mathrm{Me}) \mathrm{O} \cdot \mathrm{Li}(\mu-\mathrm{Me})\left(\mu-\mathrm{NMe}_{2}\right) \cdot \mathrm{Al}(\mathrm{Me})_{2}\right]$, a dative coordination leading to an energy saving of $-15.8 \mathrm{kcal} \mathrm{mol}^{-1}$, are, on the basis of the new information established here, not relevant to the actual experimental reagent $\mathbf{1}$ employed in bulk THF solution. This is because all the mixed lithium-aluminium species present in bulk THF solution are solvent separated and so the $\mathrm{Li}$ cannot cooperate with $\mathrm{Al}$ by providing the anisole with a coordination point adjacent to the amido ligand attached to the Al. In other words no complex induced proximity effect would be possible. We confirmed this experimentally by showing that the solvent-separated aluminate $\left[\left\{\mathrm{Li}(\mathrm{THF})_{4}\right\}^{+}\left\{\mathrm{Al}(\mathrm{TMP})\left({ }^{\mathrm{i}} \mathrm{Bu}\right)_{3}\right\}^{-}\right] \quad \mathbf{1} \cdot(\mathrm{THF})_{4}$ is incapable of metallating anisole in bulk THF solution.

In earlier work, we also performed DFT calculations considering the feasibility of a structure of putative $\mathbf{2}$. THF of formula $\left[\mathrm{THF} \cdot \mathrm{Li}(\mu-\mathrm{TMP})_{2} \mathrm{Al}\left({ }^{\mathrm{i}} \mathrm{Bu}\right)_{2}\right] .{ }^{12}$ These calculations used the Gaussian 03 package with geometry optimisation using the B3LYP density functionals and the 6-311(d,p) basis set with zero point energy corrections. While this study confirmed the most energetically stable arrangement of $\mathbf{2} \cdot \mathbf{T H F}$ has two bridging TMP ligands with the two terminal ${ }^{\mathrm{i}} \mathrm{Bu}$ ligands on $\mathrm{Al}$, significantly it also exposed the relative instability of $\mathbf{2} \cdot \mathbf{T H F}$ with respect to either its homometallic components LiTMP and (TMP)Al $\left({ }^{\mathrm{i}} \mathrm{Bu}\right)_{2}$ or THF solvates thereof. Depending on the homometallic components employed this instability ranged from +14.16 to $+20.60 \mathrm{kcal} \mathrm{mol}^{-1}$ (Scheme 9).

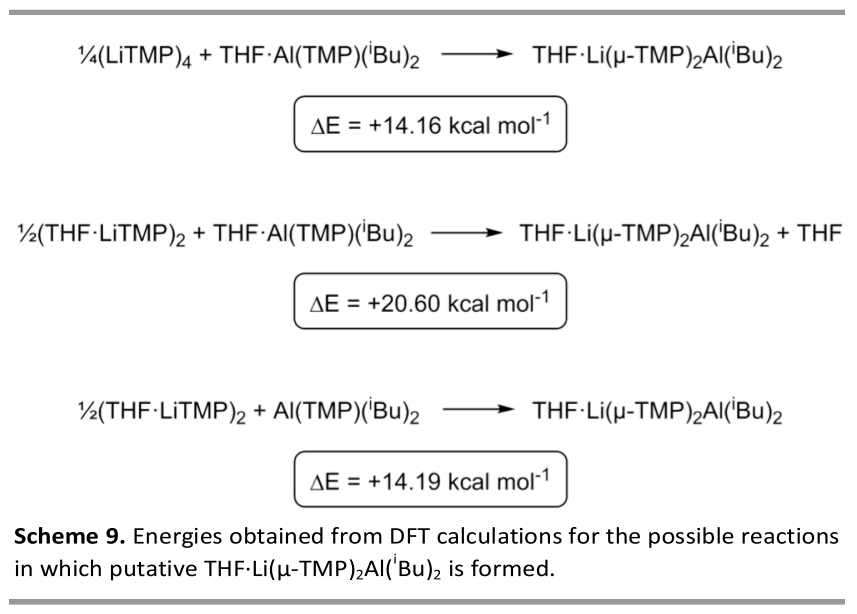

To shed more light on $\mathbf{2}$ having accrued much more knowledge on the experimental system through this study we have carried out additional calculations using the same parameters. To start we modelled a THF-free version of $\mathbf{2}, \mathrm{Li}(\boldsymbol{\mu}-\mathrm{TMP})_{2} \mathrm{Al}\left({ }^{\mathrm{i}} \mathrm{Bu}\right)_{2}$,

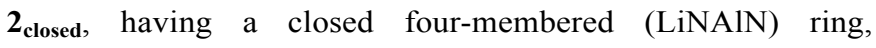
comparing it against an open version $\boldsymbol{2}_{\text {open }}$, to ascertain the effect that relaxing the steric strain by opening the ring might have on the stability of $\mathbf{2}$ (Scheme 10). Our first model of $\mathbf{2}_{\text {open }}$ was derived by breaking one of the Li-N(TMP) bonds in $\mathbf{2}_{\text {closed }}$ to leave a single $\mathrm{Li}-\mathrm{N}(\mathrm{TMP})-\mathrm{Al}$ bridge with the remaining three ligands bonded solely to Al. However, under geometry optimisation this 1-coordinate $\mathrm{Li} / 4$-coordinate $\mathrm{Al}$ model rearranged through the migration of the terminal Al-attached TMP ligand to a terminal position on $\mathrm{Li}$ to generate a more realistic 2-coordinate $\mathrm{Li} / 3$-coordinate $\mathrm{Al}$ structure, isoelectronic with crystallographically characterized (TMEDA)Li( $\mu$ TMP)Li(TMP) ${ }^{41}$ and (PMDETA)Na( $\mu$-TMP)Li(TMP). ${ }^{42}$ Relieving the steric strain by opening the LiNAIN ring in this way does indeed increase the stability with $\boldsymbol{2}_{\text {open }}$ being -5.53 kcal mol ${ }^{-1}$ more stable than $\boldsymbol{2}_{\text {closed }}$. That notwithstanding, on introducing a THF ligand to the lithium centre to mimic the experimental stoichiometry of $\mathbf{2} \cdot \mathbf{T H F}$, the structure fragmented under geometry optimisation into the homometallic components THF-LiTMP and (TMP)Al( $\left.{ }^{\mathrm{i}} \mathrm{Bu}\right)_{2}$ (Scheme 11). The energy given by the sum of these two separated homometallic components is -1614.811704 a.u. compared to -1614.805526 a.u. for $\mathbf{2}_{\text {closed }} \cdot \mathbf{T H F}$, equating to the former being more stable by $-3.87 \mathrm{kcal} \mathrm{mol}^{-1}$ [or by a more realistic $-14.19 \mathrm{kcal} \mathrm{mol}^{-1}$ if the dimeric aggregation of (THF.LiTMP) $)_{2}$ is taken into account]. Collectively these results suggest that a THF solvate of the contacted ion pair LiTMP·Al(TMP) $\left({ }^{\mathrm{i}} \mathrm{Bu}\right)_{2}$, whether in a closed or open ring arrangement would be too high in energy to exist, supporting the experimental NMR investigations which failed to detect any such species. 


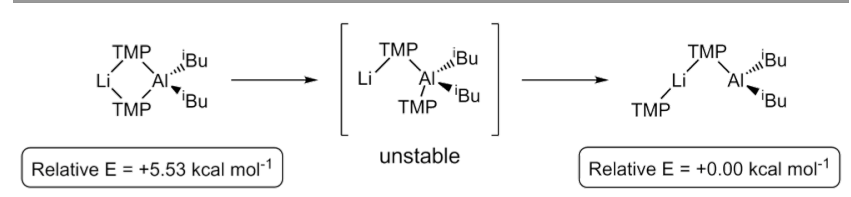

Scheme 10. ChemDraw representation of the rearrangement of Li $(\mu$ TMP) $)_{2} \mathrm{Al}(\mathrm{Bu})_{2} \mathbf{2}_{\text {closed }}$ into (TMP)Li( $\mu$-TMP)Al('Bu $)_{2} \boldsymbol{2}_{\text {open }}$ as predicted by DFT calculations.

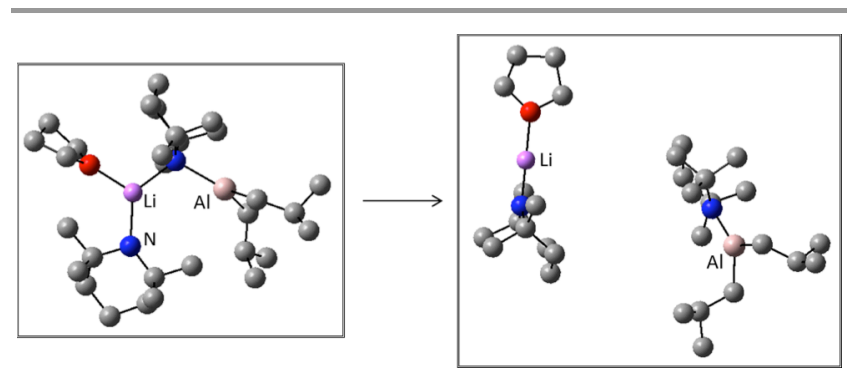

Scheme 11. Fragmentation of (THF)(TMP)Li( $\mu$-TMP)Al('Bu $)_{2}$ into its homometallic components as predicted by DFT calculations.

We have also modelled the reaction of LiTMP with anisole, which experimentally produced less than $10 \%$ of either lithiated anisole or its 2-iodo derivative following quenching with iodine. In the calculations where lithiated anisole was modelled somewhat unrealistically as an unsolvated monomer or a mono-THF-solvated monomer where the $\mathrm{Li}$ atoms have low coordination numbers the $\Delta \mathrm{E}$ values for the reactions were highly endergonic (Scheme 12). However even when the lithiated anisole was modelled more realistically as a tetramer ${ }^{43}$ or tri-THF-solvated monomer starting from (LiTMP) $)_{4}$ or $(\mathrm{THF} \cdot \mathrm{LiTMP})_{2}$ respectively as the base, the reactions are close to thermoneutral $\left(\Delta \mathrm{E}\right.$ is $+1.73 \mathrm{kcal} \mathrm{mol}^{-1}$ or $-1.18 \mathrm{kcal} \mathrm{mol}^{-1}$ respectively) though the latter one is marginally exergonic. The thermodynamics changed significantly when (TMP) $\mathrm{Al}^{\mathrm{i}} \mathrm{Bu}_{2}$ was introduced to the lithiated anisole. Depending on what form of lithiated anisole (tetramer, mono-THF-solvated monomer or triTHF-solvated monomer) was employed the $\Delta \mathrm{E}$ values ranged from $-9.39 \mathrm{kcal} \mathrm{mol}^{-1}$ to $-28.45 \mathrm{kcal} \mathrm{mol}^{-1}$, so in all three cases the reaction proved exergonic (Scheme 12). These calculations are therefore fully consistent with our experimental observations that LiTMP can lithiate anisole to only a limited extent, but that introducing the aluminium trapping reagent makes the $\mathrm{C}-\mathrm{H}$ to $\mathrm{C}$-metal transformation much more favourable.

\section{Conclusions}

This study has examined in detail the constitutions of the two most important alkali metal aluminate reagents made to date in "LiTMP·Al $\left({ }^{\mathrm{i}} \mathrm{Bu}\right)_{3}$ " 1 and "LiTMP·Al(TMP $)\left({ }^{\mathrm{i}} \mathrm{Bu}\right)_{2}$ " $\quad$ 2. In contrast to previous investigations that viewed $\mathbf{1}$ as a single species in THF solution, this study uncovers five distinct species, which appear to exist simultaneously in two connected equilibria in THF solution. Scheme 13 gives a pictorial summary of the species that exist in both hexane and THF

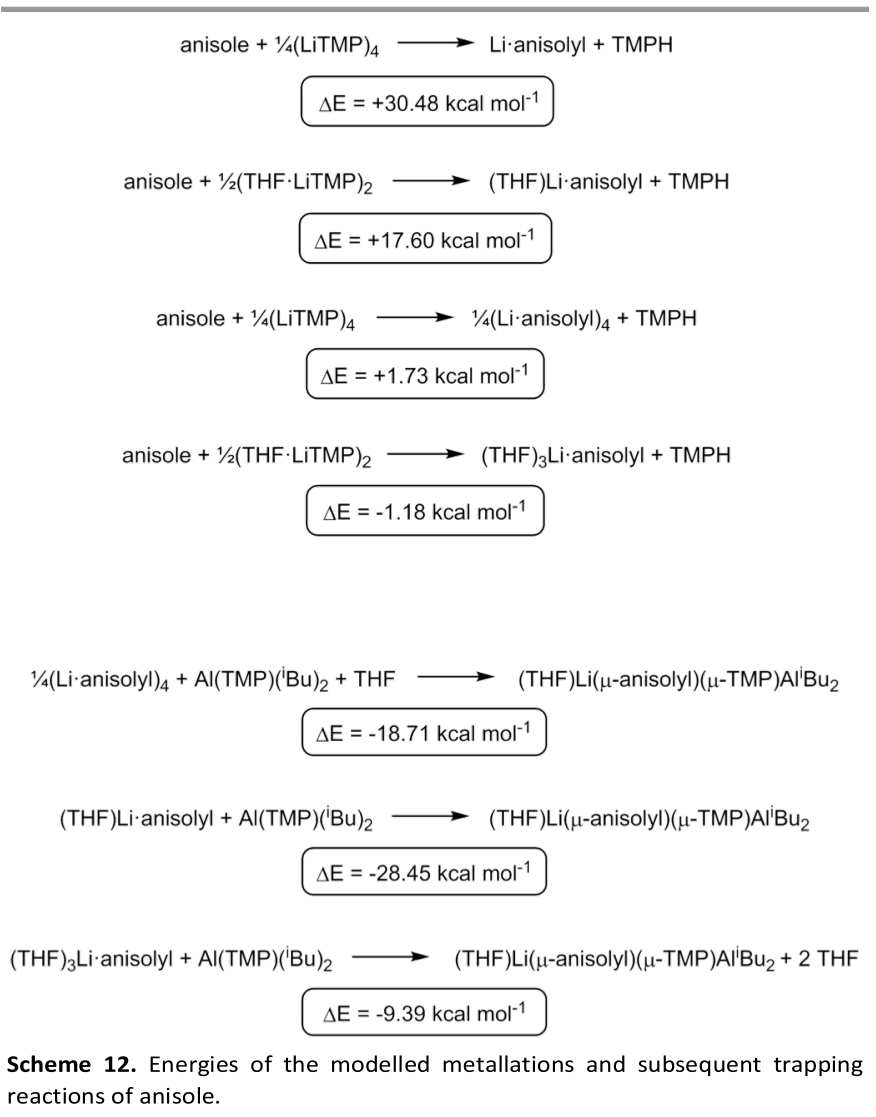

solution as well as those of $\mathbf{2}$ in the same media. One striking observation is that the single species previously identified in crystal form $\left[(\mathrm{THF}) \cdot \mathrm{Li}(\mu-\mathrm{TMP})\left(\mu-{ }^{\mathrm{i}} \mathrm{Bu}\right) \mathrm{Al}\left({ }^{\mathrm{i}} \mathrm{Bu}\right)_{2}\right], \mathbf{1} \cdot \mathbf{T H F}$, is not an active base in either hexane or THF solution using anisole as a test Brønsted acid. We confirmed that these crystals do indeed form a single species when dissolved in THF solution in the solvent-separated modification $\left[\left\{\mathrm{Li}(\mathrm{THF})_{4}\right\}^{+}\left\{\mathrm{Al}(\mathrm{TMP})\left({ }^{\mathrm{i}} \mathrm{Bu}\right)_{3}\right\}^{-}\right] \quad \mathbf{1} \cdot(\mathrm{THF})_{4} \cdot \quad$ Remarkably, however, on making up 1 in situ by adding LiTMP and $\mathrm{Al}\left({ }^{\mathrm{i}} \mathrm{Bu}\right)_{3}$ to THF solution, four other species in addition to $\left[\left\{\mathrm{Li}(\mathrm{THF})_{4}\right\}^{+}\left\{\mathrm{Al}(\mathrm{TMP})\left({ }^{\mathrm{i}} \mathrm{Bu}\right)_{3}\right\}^{-}\right] \quad \mathbf{1} \cdot(\mathrm{THF})_{4}$ are produced as identified from NMR data. Preparing authentic samples of all of these species and testing them all individually with anisole, we found that only the lithium amide LiTMP was capable of metallating anisole. Though the yield of lithiated anisole was low, it can be quickly trapped by an alkylaluminium species (we term this trans-metal-trapping), which drives the reaction forward to a high yield of "aluminated" anisole. Reagent $\mathbf{2}$ is more simple in solution remaining as its added components LiTMP and (TMP)Al( $\left.{ }^{\mathrm{i}} \mathrm{Bu}\right)_{2}$ in hexane or as THF solvates thereof when stoichiometric THF is added or in bulk THF solution. The lack of complexity can be attributed to the extra bulk of (TMP)Al $\left({ }^{\mathrm{i}} \mathrm{Bu}\right)_{2}$ compared to $\mathrm{Al}\left({ }^{\mathrm{i}} \mathrm{Bu}\right)_{3}$ which prevents its association with LiTMP and thus preventing the complicated equilibria witnessed for $\mathbf{1}$. On the basis of these findings one must advise caution against assuming that a crystalline bimetallic species grown from solution is the active reagent in 


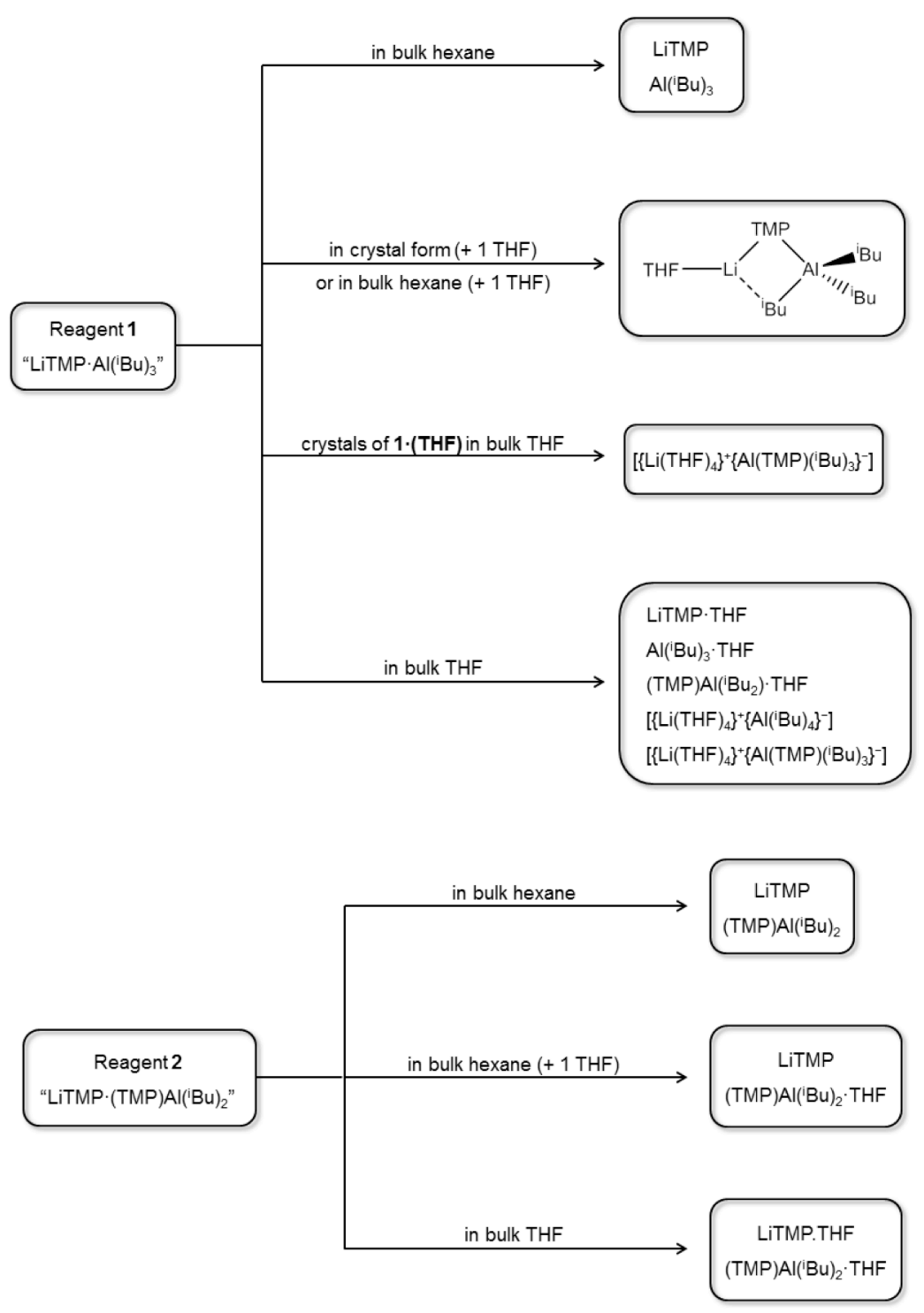

Scheme 13. Summary of the compositions of "aluminate" reagents $\mathbf{1}$ and $\mathbf{2}$. Note depending on the age of solutions, THF degradation products will also be present.

AMMAl reactions; but on the other hand, it was only through the isolation of such a metallo intermediate that its inactivity as a base could be unequivocally exposed. Looking more generally, while the complexities apparent in alkali-metalmediated metallation reactions have recently been cause to tag them as "black box chemistry", shafts of light are now becoming visible through it. In this specific case the message seems to be that unless these aluminate species are in contacted ion pair form where the alkali metal can act as a Lewis acidic coordination point for an incoming substrate to closely approach the anionic aluminium moiety, AMMAl will not generally occur; otherwise any observed metallation may be effected by the separated lithium reagent followed by rapid trapping of the newly formed lithium carbanion via an alkylaluminium reagent.

\section{Experimental Section}

\section{General methods}

All reactions and manipulations were carried out under a protective dry pure argon atmosphere using standard Schlenk techniques. Products were isolated and NMR samples prepared within an argon-filled glovebox. Hexane was dried by heating to reflux over sodium-benzophenone and distilled under nitrogen prior to use. $n \mathrm{BuLi}\left(1.6 \mathrm{M}\right.$ in hexanes) and $\mathrm{Al}(i \mathrm{Bu})_{3}$ (1.0 $\mathrm{M}$ in hexanes) were purchased from Aldrich and used as received. $i \mathrm{BuLi}$ (1.6 $\mathrm{M}$ in heptane) was purchased from ACROS and used as received. TMP(H) was obtained from Aldrich and dried over $4 \AA$ molecular sieves prior to use. LiTMP $^{26 \mathrm{~b}}$ and $\mathrm{Al}(\mathrm{TMP})\left({ }^{\mathrm{i}} \mathrm{Bu}\right)_{2}{ }^{12}$ were prepared according to 
literature procedures. NMR spectra were recorded on a Bruker AVANCE 400 NMR spectrometer, operating at $400.13 \mathrm{MHZ}$ for ${ }^{1} \mathrm{H}, 155.50 \mathrm{MHz}$ for ${ }^{7} \mathrm{Li}, 104.25 \mathrm{MHz}$ for ${ }^{27} \mathrm{Al}$ and 100.62 $\mathrm{MHz}$ for ${ }^{13} \mathrm{C}$. All ${ }^{13} \mathrm{C}$ NMR spectra were proton decoupled. ${ }^{1} \mathrm{H}$ and ${ }^{13} \mathrm{C}$ spectra were referenced to the appropriate solvent signal, ${ }^{7} \mathrm{Li} \mathrm{NMR}$ spectra were referenced against $\mathrm{LiCl}$ in $\mathrm{D}_{2} \mathrm{O}$ at $0.00 \mathrm{ppm}$ and ${ }^{27} \mathrm{Al} \mathrm{NMR}$ spectra were referenced against $\mathrm{AlCl}_{3}$ in $\mathrm{D}_{2} \mathrm{O}$ at $0.00 \mathrm{ppm}$.

\section{Theoretical Calculations}

DFT calculations were performed using the Gaussian ${ }^{44}$ computational package G03. In this series of calculations the B3LYP ${ }^{45}$ density functional and the 6-311(d,p) ${ }^{46}$ basis set were used. After each geometry optimization a frequency analysis was performed. The energy values quoted include the zero point energy contribution.

\section{Synthesis of $\left[\left\{\mathrm{Li}(\mathrm{THF}){ }_{4}\right\}^{+}\left\{\mathrm{Al}\left({ }^{\mathrm{i}} \mathrm{Bu}\right)_{4}\right\}^{-}\right](3)$}

$n$ BuLi $(3.13 \mathrm{~mL}, 1.6 \mathrm{M}$ in hexanes, $5 \mathrm{mmol}$ ) was added to a mixture of THF $(4 \mathrm{~mL})$ and TMPH $(0.85 \mathrm{~mL}, 5 \mathrm{mmol})$ at $-78^{\circ} \mathrm{C}$ and the mixture was stirred for $10 \mathrm{~min}$ at $0^{\circ} \mathrm{C} . \mathrm{Al}\left({ }^{\mathrm{i}} \mathrm{Bu}\right)_{3}(5 \mathrm{~mL}$, $1 \mathrm{M}$ in hexanes, $5 \mathrm{mmol}$ ) was then added at $-78^{\circ} \mathrm{C}$ and the mixture stirred for $30 \mathrm{~min}$ at $0^{\circ} \mathrm{C}$ to give a pale yellow solution and a white solid. The reaction mixture was then heated to refluxing temperature to obtain a clear solution and subsequent bench cooling of this solution afforded colourless crystals of 3 (0.55 g, 20\%). ${ }^{1} \mathrm{H}$ NMR $\left(\mathrm{C}_{6} \mathrm{D}_{6}, 400.13 \mathrm{MHz}, 300 \mathrm{~K}\right): \delta 3.46$ (m, 16H, $\left.\mathrm{OCH}_{2} \mathrm{THF}\right), 2.37$ (sept, 4H, $\left.\mathrm{CH}_{2} \mathrm{CH}\left(\mathrm{CH}_{3}\right)_{2}\right), 1.38$ (d, $\left.24 \mathrm{H}, \mathrm{CH}_{2} \mathrm{CH}\left(\mathrm{CH}_{3}\right)_{2}\right), 1.32$ (m, 16H, $\left.\mathrm{CH}_{2} \mathrm{THF}\right), 0.07 \mathrm{ppm}(\mathrm{d}$, $\left.8 \mathrm{H}, \mathrm{CH} \mathrm{H}_{2} \mathrm{CH}\left(\mathrm{CH}_{3}\right)_{2}\right) ;{ }^{13} \mathrm{C} \mathrm{NMR}\left(\mathrm{C}_{6} \mathrm{D}_{6}, 100.62 \mathrm{MHz}, 300 \mathrm{~K}\right): \delta$ $67.75\left(\mathrm{OCH}_{2} \quad\right.$ THF $), \quad 29.55 \quad\left(\mathrm{CH}_{2} \mathrm{CH}\left(\mathrm{CH}_{3}\right)_{2}\right), \quad 28.03$ $\left(\mathrm{CH}_{2} \mathrm{CH}\left(\mathrm{CH}_{3}\right)_{2}\right), 25.48 \mathrm{ppm}\left(\mathrm{CH}_{2}\right.$ THF $)$ [note that the resonance for $\left\{\mathrm{CH}_{2} \mathrm{CH}\left(\mathrm{CH}_{3}\right)_{2}\right\}$ could not be observed in either $\mathrm{C}_{6} \mathrm{D}_{6}$ or $\left[\mathrm{D}_{8}\right] \mathrm{THF}$ solution however its existence was confirmed by a ${ }^{1} \mathrm{H}_{-}{ }^{13} \mathrm{C}$ HSQC experiment (see Figures $\mathrm{S} 21$ and $\mathrm{S} 22$ in ESI)]; ${ }^{7} \mathrm{Li}$ NMR $\left(\mathrm{C}_{6} \mathrm{D}_{6}, 155.50 \mathrm{MHz}, 300 \mathrm{~K}\right): \delta-1.19 \mathrm{ppm}$.

\section{Acknowledgements}

Dedicated to the memory of Mike Lappert, an inorganic chemist extraordinaire, whose remarkable record of research has led to numerous breakthroughs all over the periodic table.

We gratefully acknowledge the Royal Society (Wolfson Merit Award to R.E.M.), the Royal Society of Edinburgh (BP Trust Fellowship to S.D.R.), the European Research Council (ERC Starting Grant to E.H.), the University of Strathclyde/EPSRC (Doctoral Training Grants to D.L.R. and E.C.) and EPSRC (grant award no. EP/K001183/1) for their generous sponsorship of this research. Dr C. O'Hara is also thanked for his useful insights into the work as well as Dr J. A. Parkinson and Craig Irving for their help and advice regarding the NMR spectroscopic studies.

\section{Notes and references}

${ }^{a}$ WestCHEM, Department of Pure and Applied Chemistry, University of Strathclyde, Glasgow, G1 1XL (UK) Email: r.e.mulvey@strath.ac.uk
Electronic Supplementary Information (ESI) available: Additional spectroscopic and theoretical data. See DOI: 10.1039/b000000x/

1. (a) J. Clayden, Organolithiums: Selectivity for Synthesis, Elsevier, Oxford, 2002; (b) M. Schlosser, Organometallics in Synthesis, Third Manual, Wiley, Hoboken, NJ, 2013.

2. (a) M. Lappert, P. Power, A. Protchenko and A. Seeber, Metal Amide Chemistry, Wiley, Chichester, 2009; (b) R. E. Mulvey and S. D. Robertson, Angew. Chem. Int. Ed., 2013, 52, 11470-11487.

3. (a) A. Krasovskiy and P. Knochel, Angew. Chem. Int. Ed., 2004, 43, 3333-3336; (b) A. Krasovskiy, V. Krasovskaya and P. Knochel, Angew. Chem. Int. Ed., 2006, 45, 2958-2961; (c) P. Garcia-Alvarez, D. V. Graham, E. Hevia, A. R. Kennedy, J. Klett, R. E. Mulvey, C. T. O'Hara and S. Weatherstone, Angew. Chem. Int. Ed., 2008, 47, 80798081.

4. B. Haag, M. Mosrin, H. Ila, V. Malakhov and P. Knochel, Angew. Chem., Int. Ed., 2011, 50, 9794-9825.

5. (a) R. E. Mulvey, Organometallics, 2006, 25, 1060-1075; (b) R. E. Mulvey, F. Mongin, M. Uchiyama and Y. Kondo, Angew. Chem., Int. Ed., 2007, 46, 3802-3824; (c) R. E. Mulvey, Acc. Chem. Res., 2009, 42, 743-755; (d) A. Harrison-Marchand and F. Mongin, Chem. Rev., 2013, 113, 7470-7562; (e) F. Mongin and A. Harrison-Marchand, Chem. Rev., 2013, 113, 7563-7727.

6. (a) Y. Kondo, M. Shilai, M. Uchiyama and T. Sakamoto, J. Am. Chem. Soc., 1999, 121, 3539-3540; (b) W. Clegg, S. H. Dale, E. Hevia, G. W. Honeyman and R. E. Mulvey, Angew. Chem. Int. Ed., 2006, 45, 2370-2374; (c) M. Uchiyama, Y. Matsumoto, D. Nobuto, T. Furuyama, K. Yamaguchi and K. Morokuma, J. Am. Chem. Soc., 2006, 128, 8748-8750.

7. E. Hevia, D. J. Gallagher, A. R. Kennedy, R. E. Mulvey, C. T. O'Hara and C. Talmard, Chem. Commun., 2004, 2422-2423.

8. (a) C. T. O'Hara, Organomet. Chem., 2011, 37, 1-26; (b) R. E. Mulvey and S. D. Robertson, Top. Organomet. Chem., 2013, 45, 103140.

9. D. R. Armstrong, A. R. Kennedy, R. E. Mulvey, J. A. Parkinson and S. D. Robertson, Chem. Sci., 2012, 3, 2700-2707.

10. (a) S. H. Wunderlich and P. Knochel, Angew. Chem. Int. Ed., 2009, 48, 1501-1504; (b) B. Conway, E. Crosbie, A. R. Kennedy, R. E. Mulvey and S. D. Robertson, Chem. Commun., 2012, 48, 4674-4676.

11. (a) M. Uchiyama, H. Naka, Y. Matsumoto and T. Ohwada, J. Am. Chem. Soc., 2004, 126, 10526-10527; (b) H. Naka, M. Uchiyama, Y. Matsumoto, A. E. H. Wheatley, M. McPartlin, J. V. Morey and Y. Kondo, J. Am. Chem. Soc., 2007, 129, 1921-1930; (c) H. Naka, J. V. Morey, J. Haywood, D. J. Eisler, M. McPartlin, F. Garcia, H. Kudo, Y. Kondo, M. Uchiyama and A. E. H. Wheatley, J. Am. Chem. Soc., 2008, 130, 16193-16200.

12. R. E. Mulvey, D. R. Armstrong, B. Conway, E. Crosbie, A. R. Kennedy and S. D. Robertson, Inorg. Chem., 2011, 50, 12241-12251.

13. R. Campbell, E. Crosbie, A. R. Kennedy, R. E. Mulvey, R. A. Naismith and S. D. Robertson, Aust. J. Chem., 2013, 66, 1189-1201.

14. A. Unsinn, S. H. Wunderlich, A. Jana, K. Karaghiosoff and P. Knochel, Chem. Eur. J., 2013, 19, 14687-14696.

15. T. Klatt, K. Groll and P. Knochel, Chem. Commun., 2013, 49, 69536955.

16. J. Garcia-Alvarez, E. Hevia, A. R. Kennedy, J. Klett and R. E. Mulvey, Chem. Commun., 2007, 2402-2404. 
17. For full details see page $\mathrm{S} 27$ of ref $11 \mathrm{~b}$.

18. (a) A. Macchioni, G. Ciancaleoni, C. Zuccaccia and D. Zuccaccia, Chem. Soc. Rev., 2008, 37, 479-489; (b) D. Li, I. Keresztes, R. Hopson and P. G. Williard, Acc. Chem. Res., 2009, 42, 270-280.

19. (a) J. Mason, Multinuclear NMR, Plenum Press, New York and London, 1987; (b) R. Benn, E. Janssen, H. Lehmkuhl and A. Rufinska, J. Organomet. Chem., 1987, 333, 155-168; (c) R. J. Less, H. R. Simmonds and D. S. Wright, Dalton Trans., 2014, 43, 57855792 .

20. (a) I. Krossing, H. Nöth, C. Tacke, M. Schmidt and H. Schwenk, Chem. Ber./Recueil, 1997, 130, 1047-1052; (b) I. Krossing, H. Nöth and H. Schwenk-Kircher, Eur. J. Inorg. Chem., 1998, 927-939.

21. B. Conway, E. Hevia, J. Garcia-Alvarez, D. V. Graham, A. R. Kennedy and R. E. Mulvey, Chem. Commun., 2007, 5241-5243.

22. (a) M. C. Whisler, S. MacNeil, V. Snieckus and P. Beak, Angew. Chem. Int. Ed., 2004, 43, 2206-2225; (b) V. Snieckus, Chem. Rev., 1990, 90, 879-933.

23. G. Wittig and G. Fuhrmann, Ber. Dtsch. Chem. Ges., 1940, 73, 11971218.

24. H. Gilman and R. L. Bebb, J. Am. Chem. Soc., 1939, 61, 109-112.

25. See page $\mathrm{S} 22$ of ref $11 \mathrm{~b}$.

26. (a) M. F. Lappert, M. J. Slade, A. Singh, J. L. Atwood, R. D. Rogers and R. Shakir, J. Am. Chem. Soc., 1983, 105, 302-304; (b) E. Hevia, A. R. Kennedy, R. E. Mulvey, D. L. Ramsay and S. D. Robertson, Chem. Eur. J., 2013, 19, 14069-14075.

27. E. Crosbie, A. R. Kennedy, R. E. Mulvey and S. D. Robertson, Dalton Trans., 2012, 41, 1832-1839.

28. For full details see page S23 of ref $11 \mathrm{~b}$.

29. E. Crosbie, P. Garcia-Alvarez, A. R. Kennedy, J. Klett, R. E. Mulvey and S. D. Robertson, Angew. Chem. Int. Ed., 2010, 49, 9388-9391.

30. B. Conway, J. Garcia-Alvarez, E. Hevia, A. R. Kennedy, R. E. Mulvey and S. D. Robertson, Organometallics, 2009, 28, 6462-6468.

31. D. R. Armstrong, P. Garcia-Alvarez, A. R. Kennedy, R. E. Mulvey and S. D. Robertson, Chem. Eur. J., 2011, 17, 6725-6730.

32. R. E. Mulvey, Dalton Trans., 2013, 42, 6676-6693.

33. R. B. Bates, L. M. Kroposki and D. E. Potter, J. Org. Chem., 1972, 37, $560-562$.

34. J. Q. Wen and J. B. Grutzner, J. Org. Chem., 1986, 51, 4220-4224.

35. P. Renaud and M. A. Fox, J. Am. Chem. Soc., 1988, 110, 5702-5705.

36. K. Snegaroff, J.-M. L'Helgoual'ch, G. Bentabed-Ababsa, T. T. Nguyen, F. Chevallier, M. Yonehara, M. Uchiyama, A. Derdour and F. Mongin, Chem. Eur. J., 2009, 15, 10280-10290.

37. W. Clegg, B. Conway, E. Hevia, M. D. McCall, L. Russo and R. E. Mulvey, J. Am. Chem. Soc., 2009, 131, 2375-2384.

38. For prime examples see the following paper and others referenced therein: E. Nagaradja, F. Chevallier, T. Roisnel, V. Dorcet, Y. S. Halauko, O. A. Ivashkevich, V. E. Matulis and F. Mongin, Org. Biomol. Chem., 2014, 12, 1475-1487.

39. For prime examples see the following paper and others referenced therein: F. Chevallier, T. Blin, E. Nagaradja, F. Lassagne, T. Roisnel, Y. S. Halauko, V. E. Matulis, O. A. Ivashkevich and F. Mongin, Org. Biomol. Chem., 2012, 10, 4878-4885.

40. P. Garcia-Alvarez, R. E. Mulvey and J. A. Parkinson, Angew. Chem. Int. Ed., 2011, 50, 9668-9671.

41. P. G. Williard and Q.-Y. Liu, J. Am. Chem. Soc., 1993, 115, 33803381.
42. D. R. Armstrong, A. R. Kennedy, R. E. Mulvey and S. D. Robertson, Chem. Eur. J., 2011, 17, 8820-8831.

43. S. Harder, J. Boersma, L. Brandsma, G. P. M. van Mier and J. A. Kanters, J. Organomet. Chem., 1989, 364, 1-15.

44. M. J. Frisch, G. W. Trucks, H. B. Schlegel, G. E. Scuseria, M. A. Robb, J. R. Cheeseman, J. A. Montgomery Jr, T. Vreven, K. N. Kudin, J. C. Burant, J. M. Millam, S. S. Iyengar, V. Tomasi, B. Barone, B. Mennucci, M. Cossi, G. Scalmani, N. Rega, G. A. Petersson, H. Nakatsuji, M. Hada, M. Ehara, K. Toyota, R. Fukuda, J. Hasegawa, M. Ishida, T. Nakajima, Y. Honda, O. Kitao, H. Nakai, M. Klene, X. Li, J. E. Knox, H. P. Hratchian, J. B. Cross, V. Bakken, C. Adamo, J. Jaramillo, R. Gomperts, R. E. Stratmann, O. Yazyev, A. J. Austin, R. Cammi, C. Pomelli, J. W. Ochterski, P. Y. Ayala, K. Morokuma, G. A. Voth, P. Salvador, J. J. Dannenberg, V. G. Zakrzewski, S. Dapprich, A. D. Daniels, M. C. Strain, O. Farkas, D. K. Malick, A. D. Rabuck, K. Raghavachari, J. B. Foresman, J. V. Ortiz, Q. B. Cui, A. G. Baboul, S. Clifford, J. Cioslowski, B. B. Stefanov, G. Liu, A. Liashenko, P. Piskorz, I. Komaromi, R. L. Martin, D. J. Fox, T. Keith, M. A. Al-Laham, C. Y. Peng, A. Nanayakkara, M. Challacombe, P. M. W. Gill, B. Johnson, W. Chen, M. W. Wong, C. Gonzalez and J. A. Pople, Gaussian, Inc., Wallingford, CT, 2004.

45. (a) W. Kohn, A. D. Becke and R. G. Parr, J. Phys. Chem., 1996, 100, 12974-12980; (b) A. D. Becke, Phys. Rev. A, 1988, 38, 3098-3100.

46. (a) A. D. McLean and G. S. Chandler, J. Chem. Phys., 1980, 72, 5639-5648; (b) R. Krishnan, J. S. Binkley, R. Seeger and J. A. Pople, J. Chem. Phys., 1980, 72, 650-654. 